\title{
Spatial-temporal variation and impacts of drought in Xinjiang (Northwest China) during 1961-2015
}

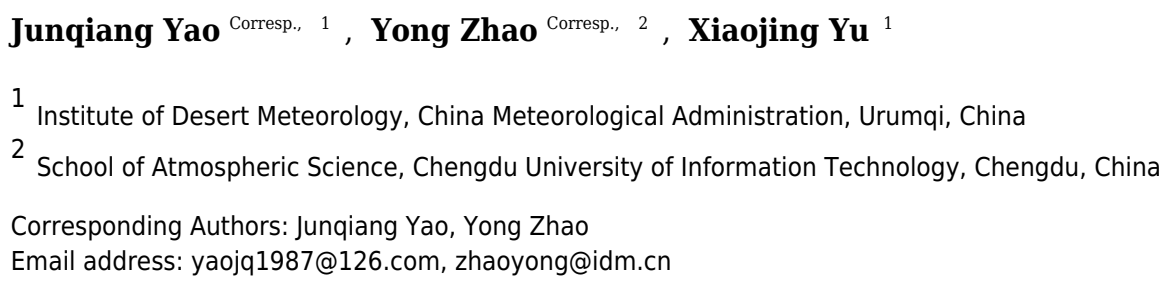

Observations indicate that temperature and precipitation patterns changed dramatically in Xinjiang, northwestern China, between 1961 and 2015. Dramatic changes in climatic conditions can bring about adverse effects. Specifically, meteorological drought severity based on the standardized precipitation index (SPI) and the standardized precipitation evapotranspiration index (SPEI) showed a decreasing trend in Xinjiang prior to 1997, after which the trend reversed. SPEI-based drought severity shows a much stronger change during 1997-2015 than the SPI, which is independent of the effect of evaporative demand. Meteorological drought severity has been aggravated by a significant rise in temperature $\left(1.1^{\circ} \mathrm{C}\right)$ over the last two decades that has not been accompanied by a corresponding increase in precipitation. As a result, the evaporative demand in Xinjiang has risen. An examination of a large spatio-temporal extent has made the aggravated drought conditions more evident. Our results indicate that increased meteorological drought severity has had a direct effect on the normalized difference vegetation index (NDVI) and river discharge. The NDVI exhibited a significant decrease during the period 1998-2013 compared to 1982-1997, a decrease that was found to be caused by increased soil moisture loss. A positive relationship was recorded between evaporative demand and the runoff coefficients of the 68 inland river catchments in northwestern China. In the future, meteorological drought severity will likely increase in arid and semiarid regions as global warming continues. 
1

\section{Spatial-temporal variation and impacts of drought in Xinjiang (Northwest China) during 1961-2015}

${ }^{1}$ Institute of Desert Meteorology, China Meteorological Administration, Urumqi, China;

${ }^{2}$ School of Atmospheric Science, Chengdu University of Information Technology, Chengdu, China;

Corresponding author: Yong Zhao (zhaoyong@idm.cn); Junqiang Yao (yaojq@idm.cn; yaojq1987@126.com) 
8

\section{ABSTRACT}

Observations indicate that temperature and precipitation patterns changed dramatically in Xinjiang, northwestern China, between 1961 and 2015. Dramatic changes in climatic conditions can bring about adverse effects. Specifically, meteorological drought severity based on the standardized precipitation index (SPI) and the standardized precipitation evapotranspiration index (SPEI) showed a decreasing trend in Xinjiang prior to 1997, after which the trend reversed. SPEI-based drought severity shows a much stronger change during 1997-2015 than the SPI, which is independent of the effect of evaporative demand. Meteorological drought severity has been aggravated by a significant rise in temperature $\left(1.1^{\circ} \mathrm{C}\right)$ over the last two decades that has not been accompanied by a corresponding increase in precipitation. As a result, the evaporative demand in Xinjiang has risen. An examination of a large spatio-temporal extent has made the aggravated drought conditions more evident. Our results indicate that increased meteorological drought severity has had a direct effect on the normalized difference vegetation index (NDVI) and river discharge. The NDVI exhibited a significant decrease during the period 1998-2013 compared to 1982-1997, a decrease that was found to be caused by increased soil moisture loss. A positive relationship was recorded between evaporative demand and the runoff coefficients of the 68 inland river catchments in northwestern China. In the future, meteorological drought severity will likely increase in arid and semiarid regions as global warming continues. 
Severe droughts have occurred more frequently as a result of recent warming, especially in Africa and Asia (Li et al., 2015; Dai, 2011; Zhang and Zhou, 2015). Drought is the most damaging, widespread, and urgent natural disaster, with negative impacts on agriculture, ecosystems, hydrology, economic and social activities, and environmental health (VicenteSerrano et al., 2010; Wang et al., 2011; Yu et al., 2013; Liu and Jiang, 2014; Chen and Sun, 2015). Droughts are often grouped into four types: meteorological, hydrological, agricultural, and socioeconomic (Council, 2004; Benitez and Domecq, 2014; Mishra and Singh, 2014).

Meteorological drought precedes and induces other types of droughts, and local feedbacks often enhance atmospheric anomalies (Trenberth et al., 1988; Dai, 2011; Potop et al., 2014; Li et al., 2015). A better understanding of drought is therefore of primary importance in order to enable early warnings of threats to environmental resources.

East Asia, which is dominated by the Pacific-Japan and Silk Road long-distance connection patterns (Zhang and Zhou, 2015), is highly influenced by drought. China is mainly located in East Asia and is strongly impacted by drought (Zhang and Zhou, 2015; Li et al., 2015). Drought severity has increased significantly in the past half-century, causing substantial damage ( $X u$ et al., 2015; Wang et al., 2012). Both Zhang and Zhou (2015) and Yu et al. (2014) report that severe drought has become more frequent since the late 1990s all over China, with particularly strong increases in southwestern and northern China (Wu et al., 2011; Yang et al., 2013). Encouragingly, however, drought severity has decreased in Xinjiang and on the Tibetan Plateau (Wang et al., 2011; Zhang et al., 2012), and the drought situation in the Huang-Huai-Hai Plain of China has remained stable for the past 30 years (Wang et al. 2015). Xu et al. (2014) presented the spatio-temporal variation of drought in China based on the 3-dimensional clustering method. 
In arid regions, widespread drying is common because precipitation depends strongly on a few precipitation events; if these events do not occur, the region becomes increasingly dry (Dai, 2011; Sun et al., 2006; Li et al., 2017). Meza (2014) reported significantly increased drought trends based on SPEI values over northern and central Chile (one of the driest regions in the arid Americas). In East Asia, most drought studies have concentrated on the eastern monsoon region although arid regions in China have sustained severe and costly droughts in the past few decades (Wang et al., 2015). For example, eastern arid China suffered a severe drought from 1994 to 1995 that caused a 32\% decrease in summer grain production (Zhang and Fang, 1995). In northwestern China, drought-affected and drought-damaged area has increased over the past two decades, and the annual damaged area reached $0.36 \times 10^{7}$ ha in the $1990 \mathrm{~s}$ (Wang et al., 2015). Zhang et al. (2012) found that droughts in Xinjiang have weakened, but that the change properties are different in different regions of Xinjiang. Using precipitation-based drought indices, Li et al. (2016) also indicated that drought severity has decreased. Tao et al. (2013) indicated that the frequency of moderate and severe droughts has decreased in the Tarim River basin, Xinjiang, but that extreme drought became slightly more prevalent after 1986. Zhang et al. (2015) assessed the vulnerability of the Tarim River basin to drought and found that drought dynamics can vary within a larger region and among indices.

Various indices have been developed to depict and monitor drought events more effectively. For example, the standardized precipitation index (SPI; World Meteorological Organization (WMO), 2012) and the Palmer drought severity index (PDSI; Palmer, 1965) have been widely used in the meteorological community to monitor drought severity (Palmer, 1965; McKee et al., 1993; Vicente-Serrano et al., 2011a). The PDSI is based on a primitive water balance that incorporates prior precipitation evaporation demand, moisture supply, runoff, and soil waterholding capacity (Vicente-Serrano et al., 2010; Zhang et al., 2015; Wang et al., 2015). Despite 
73 its physical foundation and the inclusion of evaporative demand, it lacks multi-scalar characteristics. This is a critical weakness of PDSI because drought is a multi-scale phenomenon (Vicente-Serrano et al., 2011). In contrast, SPI has the advantage of quantifying drought on different time scales and has been used by the WMO as a reference drought index (McKee et al., 1993; Hayes et al., 2011; WMO, 2012; Telesca et al., 2013). However, SPI also has shortcomings in that it considers only precipitation data without using evaporative demand, thereby neglecting the effects of global warming (Taylor et al., 2012; Teuling et al., 2013; Beguería et al., 2014; Cook et al., 2014; Zhang et al., 2015; Xu et al., 2015). More recently, the standardized precipitation evapotranspiration index (SPEI), developed by Vicente-Serrano et al. $(2010 a, b)$, takes into account the monthly climatic water balance (the difference between precipitation and reference evapotranspiration, P-PET) rather than using only precipitation. It combines the multi-scalar character of the SPI and the sensitivity of PDSI with changes in evaporative demand (Wang et al., 2015). Vicente-Serrano et al. (2015) provided the contribution of precipitation and evaporative demand to drought indices for different climates, and SPEI reflects the most evident sensitivity to PET, which is mainly controlled by aridity. Vicente-Serrano et al. (2015) also used the SPEI to reveal the increased drought severity caused by temperature rise in southern Europe. Hence, SPEI has proven to be an effective tool for monitoring and studying recent droughts under warming. Recently, it has been used in diverse studies that have analyzed drought variability, drought atmospheric mechanisms, and drought impacts over many parts of the world, including Asia, North America, Africa, Europe, and Australia (Allen et al., 2011; Potop 2011; Abiodun et al., 2013; Wang et al., 2015; Zhang et al., 2016).

In arid regions, droughts result in significant water shortages that have critical repercussions on socioeconomic development (Zhang et al., 2012; Su et al., 2015). The dynamics of droughts 
97

may become more sensitive under climate change (Jenkins and Warren, 2015), and the risk of drought has increased as a result of the global warming that has occurred over the past halfcentury (Zhang et al., 2016). Arid regions in northwestern China now face severe drought risk and water crises. Obtaining a better understanding of drought variation in the past is critical to managing drought risk and water crises in the future (Zhang et al., 2012; Xu et al., 2015a). This study aims to: (1) determine the spatio-temporal variations of drought in Xinjiang, northwestern China ; (2) provide evidence of increasing drought severity caused by temperature rise; and (3) evaluate the response of NDVI and hydrology to drought.

\section{MATERIALS AND METHODS}

The study region corresponds to Xinjiang, the largest province in China, which is located in the Eurasian hinterland. The province roughly spans the area between $73.66^{\circ} \mathrm{E}-96.38^{\circ} \mathrm{E}$ and $34.42^{\circ} \mathrm{N}-49.17^{\circ} \mathrm{N}$ and covers an area of $1.66 \times 10^{6} \mathrm{~km}^{2}$. The province is primarily characterized by desert and grasslands, and contains three mountain ranges, the Tianshan, Altai, and Kunlun Mountains, that are surrounded by vast desert basins (Fig. 1) (Zhang et al., 2012; Wang et al., 2014; Chen et al., 2014). Xinjiang is divided by the Tianshan Mountains into northern and southern Xinjiang, resulting in mountain-basin systems with different hydrological conditions (Xu et al., 2004). Xinjiang is far from any maritime influences and receives only about $158 \mathrm{~mm}$ of precipitation a year, making it one of the driest areas in the world (Bai et al., 2014). The precipitation distribution exhibits a clear summer pattern, reaching its maximum between May and August.

Continuously observed monthly temperature and precipitation readings from 76 stations in Xinjiang were provided by the China Meteorological Administration (CMA) for the period 1961-2015. To guarantee consistency, the monthly data were checked to ensure that they met the 
expected standards. The standard requires strict quality control processes including extreme inspection, time consistency check, and others before releasing these data. Pan evaporation data for northwestern China for 1961-2010 were obtained from Li et al. (2013). Soil moisture data for the period 1980-2010 were provided by the National Meteorological Information Center (NMIC), and the depths of the five soil layers range from 0 to 10,10 to 20,20 to 30,30 to 40 , and 40 to 50 $\mathrm{cm}$.

Streamflow and lake level data were obtained from the Dashankou station and from Bosten Lake, which are connected by the Kaidu River. This river descends from the southern slopes of the Tianshan Mountains (Chen and Chen, 2014) and runs through large irrigated areas into Lake Bosten. The Dashankou station is located at the foot of the Tianshan mountains.Data from both stations Observed streamflow and level data were provided by the Xinjiang Hydrology Bureau. The runoff coefficient, which is defined as the ratio between precipitation and streamflow over a given time period (Chow et al., 1988), and the monthly runoff coefficient was calculated for the period 1961-2012.

Remote sensing is a very effective method for estimating important information about spatio-temporal changes in vegetation conditions (Gomez et al., 2008; Coops et al., 2009). The Normalized Difference Vegetation Index (NDVI) (Rouse, 1974) is widely used as a proxy indicator of vegetation change and can be derived from the Advanced Very High Resolution Radiometer (AVHRR) sensor on the National Oceanic and Atmospheric Administration (NOAA) Polar Operational Environmental Satellite (POES) series, among others (Gomez et al., 2008; Eastman et al., 2013). The newest version of the Global Inventory Modelling and Mapping Studies-NDVI third-generation (GIMMS-NDVI3g) datasets has been recently released with a spatial resolution of $8 \mathrm{~km}$ and a 15-day temporal frequency (Zhu et al., 2013). The 
143 GIMMS-NDVI3g data for Xinjiang were extracted for the period 1982 to 2013 and used in this 144 study.

145 SPI and SPEI were used to quantify drought, as their multi-scalar character helps to determine 146 drought variability. SPEI is calculated based on the climatic balance between monthly 147 precipitation and atmospheric evaporative demand (monthly potential evapotranspiration, ET), whereas SPI includes only input monthly precipitation data. We employed the Thornthwaite (1948) model approach to calculate the ET. Thornthwaite (1948) correlated monthly mean temperature with PET, as determined from the water balance. Willmott et al. (1985) modified Thornthwaite's original approach slightly by introducing parameterization for a limited range of average air temperature $T$ (Units: $\left.{ }^{\circ} \mathrm{C}\right)$ :

$$
\mathrm{PET}=\left\{\begin{array}{lr}
0 & \mathrm{~T}<0 \\
16\left(\frac{N}{12}\right)\left(\frac{N D M}{30}\right)\left(\frac{10 T}{I}\right)^{m} & 0 \leq T<26.5 \\
-415.85+32.24 T-0.43 T^{2} & \mathrm{~T}>26.5
\end{array}\right.
$$

where $N$ is maximum number of sun hours, $N D M$ is number of days in the month, and $I$ is heat index, which is calculated as the sum of 12 monthly index values:

$$
I=\sum_{i=1}^{12}\left(\frac{T}{5}\right)^{1.514} \mathrm{~T}>0
$$

and $m$ is a coefficient that depends on $I$ :

$$
m=6.75 \times 10^{-7} I^{3}-7.71 \times 10^{-5} I^{2}+1.79 \times 10^{-2} I+0.492 .
$$

The SPEI is quantified through the following steps: (a) calculating the PET; (b) determining the deficit or surplus accumulation of a climate-water balance (P-PET) at different time scales; and (c) normalizing the water balance into probability distribution to obtain the SPEI series. In our study, Gamma distribution was chosen to calculate SPI for different time scales, and the SPEI index was calculated using the three-parameter log-logistic probability distribution. 
164

165

166

167

SPI and SPEI were calculated for each month of the year, and time scales of 1, 3, 6, and 12 months were selected for analysis. The SPI and SPEI drought categories are listed in Table 1. Drought duration was calculated at each station for each year, and a threshold value of - 1 was used to determine a drought condition. The duration of a drought was interpreted as the number of dry months. Regional drought durations were estimated for each year.

The nonparametric Mann-Kendall method (M-K) recommended by the WMO (Mann, 1945, Kendall, 1975; Sneyers, 1990) was used to investigate the temporal evolution of climate and drought indices from 1961 to 2015 . This method has been used to investigate the significance of trends in various hydro-meteorological factors, including precipitation, runoff, evaporation and drought indices (Zhang et al., 2012; Tao et al., 2014; Benitez and Domecq, 2014; Potop et al., 2014; Vicente-Serrano et al., 2014; Wang et al., 2015; Li et al., 2015). The Pearson correlation coefficient was used to investigate the relationship between drought indices and climate series.

\section{RESULTS}

\section{Temporal variations in temperature and precipitation}

From 1961 to 2015, annual mean temperature in Xinjiang, China, experienced a significant increasing trend, with a rate of increase of $0.31^{\circ} \mathrm{C} / 10 \mathrm{a}$. This is considerably higher than the rates of increase observed for China as a whole, or globally $\left(0.25^{\circ} \mathrm{C} / 10 \mathrm{a}\right.$ and $0.12^{\circ} \mathrm{C} / 10 \mathrm{a}$, respectively) (IPCC, 2013). The warming trend started to intensify during the late 1980s, then increased sharply in 1997 (Figure 2a). During the recent 17-year period (1997-2015), temperature has been in a highly volatile state, making this the warmest period in the last half-century. However, although temperatures remained elevated during this period, there was no clear increase. As a result, the period from 1997-2015 is now referred to as a "hiatus" (Easterbrook, 2008; Easterling and Wehner, 2009; Kaufmann et al., 2011). Spatially, the main areas of accelerated warming 
appear to be in northern Xinjiang. Over the past half-century, precipitation has exhibited a slight increasing trend and greater decadal fluctuations. Annual precipitation remained relatively stable from the 1960s to the mid-1980s, then began to increase sharply in 1987 (Figure 2b). The most humid decade was the $2000 \mathrm{~s}$, but without the continuously increasing trend of the $1990 \mathrm{~s}$.

Spatially, the area with the most significant increase in precipitation was mainly in northern Xinjiang. Some researchers have suggested that these data show a warmer and wetter trend for Xinjiang (Shi et al., 2003; Fang et al., 2013; Chen et al., 2015).

\section{Relationship between the SPI and SPEI drought indices}

Monthly SPI and SPEI were estimated at four time scales (1, 3, 6, and 12 months) for all selected stations from 1961 to 2015. The average SPI and SPEI were then calculated to characterize drought episodes in Xinjiang (Figure 3). According to historical records, the evolution of SPI and SPEI is highly consistent between stations and time scales (Cao et al., 2015). Figure 4 displays the difference between the two drought indices at four lags. It illustrates that SPEI became gradually lower than the corresponding SPI and that the difference has increased in recent decades. Moreover, these differences were more evident over 6- and 12month lags than over 1- and 3-month lags. In late 1996, the difference became as large as -1.5 .

On a 6-month time scale, SPI and SPEI showed large differences before the 1990s (Figure 4c). More wet events and fewer dry events were identified based on SPEI. Nevertheless, based on SPEI, most of the 1990s and the first decades and a half of the 21 st century qualify as some of the most drought-intense years on record. On a 12-month time scale, both indices identified the major drought periods from 1961 to 1966 and from 1976 to 1986 . However, only the SPEI was able to identify drought events between 1996 and 2015 (Figure 4d). In general, SPEI confirmed that the most frequent droughts occurred in the 1960s, 1970s, late 1990s, and late 2000s, whereas 
210 SPI identified drought conditions during the 1960s, 1970s, and early 1980s, as well as humid 211 periods.

212 The increase in temperature enhanced ET, causing excessive water consumption and thus

213

214

215

216

217

218

219

220

221

222

223

224

225

226

227

228

229

230

231

232

lowering the value of SPEI. In arid regions, water consumption occurs mainly through actual evapotranspiration (AE/mm), as there is ample energy (radiation) available for evaporation. For

the 21 st century, the number of drought episodes identified by SPEI was greater than the number identified by SPI due to the enhanced evaporation amount.

Figure 5 shows the Pearson's $r$ coefficients between SPI and SPEI estimated at 1-, 3-, 6-, and 12-month lags in the series for all of Xinjiang, northern Xinjiang, and southern Xinjiang from 1961 to 2015. Most observations showed a high correlation between SPI and SPEI. The correlations among the drought indices was notably stronger over shorter time scales than over longer time scales, varying between 0.67 for a 1 -month lag and 0.44 for a 12 -month lag for the whole region. Spatially, the correlation between 12-month SPI and SPEI was very high in Xinjiang, with $86 \%$ of observations reaching the $99 \%$ significance level. Correlations between SPEI and SPI were notably stronger in northern Xinjiang than in southern Xinjiang at all four time scales (Fig. 5).

\section{Evidence of increasing drought caused by temperature rise}

The 12-month SPI and SPEI series showed coherent variation in Xinjiang before 1997 (Fig. 6). A major drought in Xinjiang was observed from 1975 to 1986, after which both indices identified smaller drought events between 1987 and 1996, with a trend towards more positive values. Nevertheless, SPEI also identified increased drought severity relative to SPI between 1997 and 2015 (Figs. 6a and 6c). The increased drought severity is due mainly to the temperature rise in Xinjiang, which is better captured by SPEI than by SPI. 
Figure 7 shows the spatial patterns of the 12-monthly SPI and 12-monthly SPEI trends for the 1961-1996 and 1997-2015 at each station. From 1961 to 1996, SPI evolved in a positive direction (meaning wetter conditions) over Xinjiang; increased drought was recorded at only a few stations (Fig. 7a). For 12-monthly SPEI, about $72.5 \%$ of stations showed increasing trends (Fig. 7c). SPI showed increasing drought conditions from 1997 to 2015, during which time about $47.1 \%$ of stations in northwestern and southwestern Xinjiang had larger trend magnitudes (Fig. 7b). SPEI indicated a more obvious decrease than SPI at 70.5\% of stations (Fig. $7 d$ ).

Furthermore, northwestern Xinjiang and Kunlun Mountain display obvious wetting trends during this period. Hence, both indices indicated increasing drought severity in Xinjian over the last two decades, but SPEI identified a larger drought region than SPI, which neglects the effect of ET. The main driving force underlying evaporation changes in arid China is the aerodynamic component, specifically wind speed, while the radiative component has a minor impact (Li et al., 2013). Observed vapor pressure deficit (VPD) was also a primary contributor to ET changes after the early 1990s (Li et al., 2013). The VPD exhibited an obvious increasing trend, with a rate of $3.9 \mathrm{~mm} /$ year from 1994 to 2010 (Li et al., 2013). This trend reduced moisture supply and increased the atmospheric water-holding capacity as a result of the increase in temperature. The strengthened evaporative demand was evidenced by trends in potential evaporation in Xinjiang, which were observed directly by pan evaporation (Fig. 8). Annual pan evaporation data exhibit a strong decreasing trend with a rate of $-6.0 \mathrm{~mm} /$ year from 1975 to 1993 . Since 1994, however, this trend has reversed upward at a rate of $10.7 \mathrm{~mm} / \mathrm{year}$.

\section{Spatio-temporal extent of drought}

Figure 9 illustrates the average number of dry or wet months in each year from 1961 to 2015. Relatively long series of dry months appeared in the early 1960s, late 1970s, and early 1980s, and very long series of dry months occurred in the late 1990s until the 2010s. In contrast, 
257 a several series of wet months occurred in the early 1970s, and a very long series of wet months 258 occurred from the late 1980s until the middle of the 1990s. The temporal variation in the number 259 of dry months showed a significantly increasing trend $(0.54 \mathrm{mo} / 10 \mathrm{a}, p<0.01)$. Before 1997 , there 260 were fewer than two dry months per year but the number of dry months has increased since then. 261 The average number of dry months in recent years was greater than four, and the maximum 262 number of dry months in a year was greater than seven (from 2007 to 2009).

Figure 10 shows the mean number of dry months per year at different SPEI time scales from 264 1961 to 2015 . The results from the two indices are generally comparable before the late 1990s. The number of droughts identified at 1-, 3-, and 6-month time scales was slightly less than at the 12-month time scale. However, a sharp transition occurred by the late 1990s. The average number of dry months for SPEI-12 was four, which was greater than the numbers for shorter SPEI time scales (3.5 months for SPEI at 3 and 6 months, and 2.7 months for SPEI at 1 month). However, because the high frequency noise is attenuated over longer periods, it is expected that the 12-month SPEI will have a higher number of dry months. Especially between 2007 and 2009, the number of dry months in SPEI-12 greatly exceeds the shorter accumulation periods (7.0 months for SPEI-12, 5.2 months for SPEI-3 and SPEI-6, and 3.3 months for SPEI-1). Periods probably increase this difference.

Next, the percentage of stations with dry months (SPEI $\leq-1)$ was considered to investigate the spatial variation of drought severity. Figure 11 shows the variation in the percentage of stations with more than 3 and 6 dry months at a 12-month time scale during the period 19612010. The other cases are not listed here. A significant increasing trend in the percentage of stations with more than three dry months was found in Xinjiang, with a rate of increase of $5.80 \%$ /decade (Figure 11). The highest number of droughts occurred after 1997, when about 
$54.93 \%$ of stations experienced drought. Widespread and severe droughts (those for which the percentage of stations recording drought exceeds 60\%) were recorded in 1962, 1974, 1978, 1997-1998, 2000-2001, 2007-2009, and 2012, with 62\%, 64\%, 80\%, 71\%, 67\%, 60\%, 61\%, $75 \%, 89 \%, 89 \%$, and $82 \%$ of stations recording drought, respectively.

This analysis shows that drought conditions have been aggravated over the last two decades in Xinjiang. The percentage of stations with more than six dry months also showed a significant increasing trend, with a rate of $4.91 \% /$ decade $(\mathrm{p}<0.05)$ (Figure 11). During the period 20072008 in particular, more than $71 \%$ of stations sustained drought conditions for more than six months.

Figure 12 shows the severe drought events mentioned above. The 1974 drought mostly affected northern Xinjiang, particularly the northern slopes of the Tianshan Mountains, Urumqi, the Changji region, and the Altay region (Shi 2006). The 2008 drought was one of the most serious droughts in recent times with regard to drought duration, area affected, and agricultural, livestock, and economic losses. The drought, which lasted from spring to autumn, was mainly located in southern Xinjiang, the Tianshan Mountain region, the Yili Valley, Tacheng, Altay, and the Hami region. It was reported that the drought caused the loss of 1.22 million hectares of crops, 28 million hectares of grasslands, and one billion yuan in direct economic losses (Cao et al., 2015; CMA 2010). The 2009 drought was persistent and affected southern Xinjiang, while a slightly less severe drought occurred in the eastern and northwestern parts of Xinjiang. The drought caused the Tarim River, China's longest inland river, to run dry over more than 1100 kilometers (CMA 2010). In the spring and summer of 2012, northern Xinjiang and the Tianshan Mountains experienced severe droughts, particularly in the Yili, Tacheng, and Altay regions. The droughts reduced the yield of industrial tomatoes (in one of the world's three largest industrial 
tomato-growing areas) to less than half that of the year before

(http://finance.sina.com.cn/roll/20121016/110213381605.shtml).

\section{Response of vegetation NDVI and hydrology to drought}

Increased meteorological drought severity should be evident in increased impacts on drought-sensitive systems, especially natural vegetation. The NDVI reflects ecosystem processes and is a critical indicator for monitoring climate dryness and wetness. Yao et al. (2017) analyzed the response of vegetation NDVI to climate change over Xinjiang from 1982 to 2013 and found that the NDVI increased from 1982 to 1997, then decreased significantly after 1997.

The results of this study confirm a strong negative correlation $(r=-0.52 ; p<0.01)$ between NDVI and an increase in PET, but the correlation between NDVI and precipitation does not show a clear relationship. Nevertheless, the relationship between the NDVI and SPEI $(r=0.37$; $p<0.01)$ shows a stronger correlation than that between the NDVI and SPI $(r=0.22 ; p<0.05)$, implying that the decrease in vegetation NDVI is mainly controlled by PET. PET influences vegetation NDVI by affecting soil moisture and plant transpiration, which eventually leads to soil moisture loss (Li et al., 2015). Soil moisture in Xinjiang has recently shown a marked decreasing trend, which is especially obvious in shallow soil layers (Figure 13 and Table 2). Climate warming increases soil moisture loss and cause the death of shallow-rooted plants ( $\mathrm{Li}$ et al., 2015). Consequently, NDVI decrease and soil moisture loss have almost the same effect as climate dryness.

Drought trends and their relation to water resources are directly related to hydrological drought in China (Shen and He, 1996; Zhai et al., 2010). Drought at the 12-month time scale is relevant for hydrological impacts (Benitez and Domecq, 2014). Runoff in some of the larger rivers in arid China has shown a widespread "sharp" increasing trend from 1961 to 2010 (Chen et al., 2015), and a "sharp" increase in the early 1990s, especially in the Tarim River basin (Chen 
et al., 2015). In this study, long series of runoff data for typical rivers in Xinjiang were analyzed, including for the Kaidu River (one of the four main source streams of the Tarim River), which has not been influenced by human interference and regulation. This analysis discovered a significant upward trend $(11.2 \mathrm{~mm} /$ decade, $p<0.01)$ in measured runoff in the Kaidu River from 1960 to 2010 (Figure 14b), with a 26.5\% increase after the early 1990 s. Figure 14 (a and b) displays the evolution of runoff and precipitation in the Kaidu River basins, and there have a strong correlation $(r=0.70 ; p<0.01)$. Nevertheless, the runoff coefficient shows a significant increase since 1990 (Figure 14c), implying that runoff has increased more than precipitation. Figure 15 presents the positive relationship between PET and the runoff coefficient of 68 rivers in arid China. This coincides with a marked increase in mountain temperature and drought indices (Figure 14d), suggesting that increased meltwater from glaciers and snowpack may be contributing to incremental runoff. Furthermore, it is noteworthy that the rate of increase in precipitation has diminished since the beginning of the $21^{\text {st }}$ Century (Figure 14a). Hence, the decrease in drought indices is consistent with decreased P (Figure 14d). Lake Bosten, China's largest inland freshwater lake, is the outlet lake of the Kaidu River. The decrease in observed lake level has become more acute since the start of the 21 st century, coinciding with the evolution of increased drought (Figure 14e). In addition, these developments are associated with large lake areas that favor direct evaporation under increased PET.

\section{DISCUSSION}

Climate change in Xinjiang is complex and responds sensitively to global warming (Chen et al., 2012; Xu et al., 2013; Chen et al., 2015). Shi et al. (2002) found a climatic transition from warmdry to warm-wet in Xinjiang in the early $21^{\text {st }}$ century based on observed data. Most evidence for hydroclimatic and environmental change in Xinjiang since then has strongly supported this 
351 observation (Shi et al., 2003; Shi et al., 2007; Zhao et al., 2009; Xu et al., 2010; Li et al., 2011;

352 Li et al., 2012; Li et al., 2013; Yao et al., 2017). Fang et al. (2013) further confirmed this

353 climatic transition in Xinjiang based on Coupled Model Inter-comparison Project-Phase 5

354 (CMIP5) model simulation results. We provide a latest observed data of climate change under

355 global warming. The data indicate that warming started to accelerate during the late 1980s and

356 underwent a sharp increase in 1997, after which temperatures remained highly stable (the

357 warming hiatus). Meanwhile, precipitation exhibited a sharp increase in 1987, but has remained

358 in a relatively stable state since then. As mentioned earlier, temperature and precipitation have

359 exhibited a dramatic change under global warming.

360 Li et al. $(2016 a ; 2016 b)$ demonstrated that drought relief resulted from the local climate

361 becoming warmer and wetter in Xinjiang, as indicated by the precipitation-based drought

362 indices. Zhang et al. (2012) also confirmed that SPI-based evaluations of drought severity in

363 Xinjiang have lessened in recent years. In contrast, the results of this study indicate that SPEI-

364 based drought severity has been aggravated in the last two decades as a result of temperature

365 rise. The Xinjiang region has been experiencing increased drought severity since 1997 as a

366 consequence of a significant increase in temperature $\left(1.1^{\circ} \mathrm{C}\right.$ for two decades $)$ coupled with an

367 insignificant increase in precipitation $(3.5 \mathrm{~mm} / 10 \mathrm{a})$. Drought conditions have been exacerbated

368 by higher evaporative demand, which increased by $10.7 \mathrm{~mm}$ annually from 1994 to 2010 .

369 The major difference between the precipitation-based indices and SPEI is the

370 meteorological factors used to calculate the indices, i.e., $\mathrm{P}$ and P-PET respectively. SPI considers

371 only climatic water supply, whereas SPEI considers both climatic water supply and demand $(X u$

372 et al., 2015b). Precipitation is a critical meteorological driver of drought, but rising temperatures

373 are playing an increasingly strong role in influencing drought severity (Xu et al., 2015b; Vicente- 
374 Serrano et al., 2014). SPEI is therefore a better indicator than SPI under climatic warming

375 because it is sensitive to temperature.

376 Climate change effects on droughts have been found to exhibit similar characteristics at 377 specific sites. Vicente-Serrano et al. (2014) suggested that drought severity has increased in 378 southern Europe as a consequence of temperature rise. Sun and Ma (2015) also reported 379 increasing drought severity over the Loess Plateau in China because of the combined effects of a 380 significant increase in average temperature and an insignificant decrease in precipitation. The 381 results described here are consistent with these results. This pattern of drought severity caused by 382 temperature rise is probably applicable to other arid and semiarid areas of the world.

\section{CONCLUSIONS}

In this research, two multi-scalar drought indices were used: the Standardized Precipitation Index (SPI) and the Standardized Precipitation-Evapotranspiration Index (SPEI). The evolution of meteorological drought was investigated in Xinjiang, northwestern China, for the period 19612015 .. This study provides evidence for increasing drought severity caused by temperature rise and discusses the effects on vegetation and water resources. A summary of the main results follows:

(1) Temperature and precipitation in Xinjiang exhibited a dramatic change between 1961 and 2015. Temperature experienced a sharp increase in 1997, after which it has remained highly volatile and exhibited a recent warming hiatus. Precipitation showed a sharp increase in 1987, but the increasing trend has diminished over the past two decades.

(2) The evolution of SPI and SPEI displayed a high level of agreement for most stations and time scales. SPI and SPEI showed increasing trends before 1997, after which the trends reversed. Between 1997 and 2015, SPI showed increasing drought conditions at $47.1 \%$ of the stations in 
northwestern and southwestern Xinjiang, especially at stations in the southwestern Tarim River Basin. SPEI showed increased drought severity across $70.5 \%$ of stations.

(3) SPEI-based drought severity was significantly aggravated relative to that based on SPI, which is independent of the effect of evaporative demand. Potential evaporation exhibited a strong increasing trend at a rate of $10.7 \mathrm{~mm} /$ year. Meteorological drought severity over the last two decades has been exacerbated by greater evaporative demand caused by a significant increase in temperature $\left(1.1^{\circ} \mathrm{C}\right)$ coupled with an insignificant increase in precipitation $(0.35 \mathrm{~mm}$ annually). Increased meteorological drought severity has had a direct effect on NDVI and river discharge.

\section{REFERENCES}

Abiodun, B. J., Salami, A. T., Matthew, O. J., Odedokun, S. 2013. Potential impacts of afforestation on climate change and extreme events in Nigeria. Clim. Dyn. 41(2): 277-293 DOI org/10.1007/s00382-012-1523-9

Allen, K. J., Ogden, J., Buckley, B. M., Cook, E. R., Baker, P. J. 2011. The potential to reconstruct broadscale climate indices associated with southeast Australian droughts from Athrotaxis species, Tasmania. Clim. Dyn. 37: 1799-1821 DOI org/10.1007/s00382-011$1011-7$

Benitez, J. B., and Domecq, R. M. 2014. Analysis of meteorological drought episodes in Paraguay. Climatic change 127(1): 15-25 DOI 10.1007/s10584-014-1260-7.

Beguería, S., Vicente-Serrano, S. M., Reig, F., and Latorre, B. 2014. Standardized Precipitation Evapotranspiration Index (SPEI) revisited: parameter fitting, 
evapotranspiration models, kernel weighting, tools, datasets and drought monitoring. Int. J. Climatol 34: 3001-3023 DOI 10.1002/joc.3887.

Burton, I., R. W. Kates, and G. F. White. 1978. The Environment as Hazard, Oxford University Press, 240 pp.

Cao, Y. P., Nan, Z. T., and Cheng, G. D. 2015. GRACE gravity satellite observations of terrestrial water storage changes for drought characterization in the arid land of northwestern China. Remote Sensing 7(1):1021-1047 DOI 10.3390/rs70101021.

Chen, Z. S., and Chen, Y. N. 2014. Effects of climate fluctuations on runoff in the headwater region of the Kaidu River in northwestern China. Front. Earth Sci 8(2): 309-318 DOI 10.1007/s11707- 014-0406-2.

Chen, H.-P., and J.-Q. Sun. 2015. Drought response to air temperature change over China on the centennial scale. Atmos. Oceanic Sci. Lett. 8: 113-119 DOI 10.3878/AOSL20140089.

Chen, Y. N, Li Z, Fan Y, Wang H, Deng H. 2015. Progress and prospects of climate change impacts on hydrology in the arid region of northwest China. Environ. Res 139: 11-19 DOI 10.1016/j.envres.2014.12.029.

Chen, Y. N., Yang, Q., Luo, Y. 2012. Ponder on the issue of water resources in the arid region of northwest China. Arid Land Geogr 35 (1): 1-9 (in Chinese).

Chow VT, Maidment DR, and Mays LW. 1998. Applied Hydrology, McGraw-Hill, New York, USA, p 15.

CMA. 2010. Atlas of meteorological drought in China. China Meteorological Press: 50-108pp (in Chinese).

Coops, N. C., Ferster, C. J., Waring, R. H., and Nightingale, J. 2009. Comparison of three models for predicting gross primary production across and within forested ecoregions in the 
contiguous United States. Remote Sensing of Environment 113 (3): 680-690 DOI

\subsection{6/j.rse.2008.11.013.}

Cook, B. I., Smerdon, J. E., Seager, R., and Coats, S. 2014. Global warming and 21st century drying. Clim. Dyn DOI 10.1007/s00382-014-2075-y.

Council, A. 2004. AMS statement on meteorological drought. Bull. Am. Meteor. Soc 85: 771773.

Dai, A. 2011. Drought under global warming: a review. Wiley Interdisciplinary Reviews: Climate Change 2(1): 45-65 DOI 10.1002/wcc.81.

Davis, M. A., and M. Pelsor. 2001. Experimental support for a resource-based mechanistic model of invisibility. Ecol. Lett. 4: 421 - 428 DOI 10.1046/j.1461-0248. 2001.00246.x.

Dubrovsky, M., Svoboda, M. D., Trnka, M., Hayes, M. J., Wilhite, D. A., Zalud, Z., and Hlavinka, P. 2009. Application of relative drought indices in assessing climate-change impacts on drought conditions in Czechia. Theor. Appl. Climatol 96: 155-171 DOI 10.1007/s00704-008-0020-X.

Eastman, J. R., Sangermano, F., Machado, E. A., Rogan, J., and Anyamba, A. 2013. Global trends in seasonality of normalized difference vegetation index (NDVI), 1982-2011. Remote Sensing 5(10): 4799-4818 DOI 10.3390/rs5104799.

Easterbrook, D. J. 2008. Global cooling is here - Evidence for predicting global cooling for the next three decades. (Available at http://www. globalresearch.ca/ index. php? context= \&aid=10783.)

Easterling, D. R., and M. F. Wehner. 2009. Is the climate warming or cooling? Geophys. Res. Lett. 36, L08706 DOI 10.1029/2009GL037810. 
Fang, S., Yan, J., Che, M., Zhu, Y., Liu, Z., Pei, H., and Lin, X. 2013. Climate change and the ecological responses in Xinjiang, China: Model simulations and data analyses. Quaternary International 311: 108-116 DOI 10.1016/j.quaint.2013.08.032.

FEMA. 1995. National Mitigation Strategy: Partnerships for Building Safer Communities. Federal Emergency Management Agency: Washington, DC; 26.

Gómez-Mendoza, L., Galicia, L., Cuevas-Fernandez, M. L., Magana, V., Gómez, G., and Palacio-Prieto, J. L. 2008. Assessing onset and length of greening period in six vegetation types in Oaxaca, Mexico, using NDVI-precipitation relationships. Int J Biometeorol 52(6): 511-520 DOI 10.1007/s00484-008-0147-6.

Hayes, M., Svoboda, M., Wall, N., and Widhalm, M. 2011. The Lincoln declaration on drought indices: universal meteorological drought index recommended. Bull. Am. Meteorol. Soc 92: 485-488 DOI 10.1175/2010BAMS3103.1.

IPCC.2013. Working Group Contribution to the IPCC Fifth Assessment Report, Clim. Change, The Physical Science Basis, Summary for Policymakers.

Jenkins, K., and Warren, R. 2015. Quantifying the impact of climate change on drought regimes using the Standardised Precipitation Index. Theoretical and Applied Climatology 120(1-2): 41-54 DOI 10.1007/s00704-014-1143-X.

Kaufmann, R. K., H. Kauppi, M. L. Mann, and J. H. Stock. 2011. Reconciling anthropogenic climate change with observed temperature 1998-2008. Proc. Natl. Acad. Sci. U.S.A. 108: 11,790-11,793 DOI 10.1073/pnas.1102467108.

Kendall, M.G. 1975. Rank-correlation measures, Charles Griffin, London.

Keyantash J, Dracup JA. 2002. The quantification of drought: an evaluation of drought indices. Bulletin of the American Meteorological Society 83: 1167-1180 DOI 10.1175/15200477(2002) 083. 
Li, X., He, B., Quan, X., Liao, Z., and Bai, X. 2015. Use of the standardized precipitation evapotranspiration index (SPEI) to characterize the drying trend in southwest China from 1982-2012. Remote Sensing 7(8): 10917-10937 DOI 10.3390/rs70810917.

Li, Q., S. Yang, W. Xu, X. L. Wang, P. Jones, D. Parker, L. Zhou, Y. Feng, and Y. Gao. 2015. China experiencing the recent warming hiatus. Geophys. Res. Lett. 42: 889-898 DOI 10.1002/2014GL062773.

Li, Q., Chen, Y., Shen, Y., Li, X., and Xu, J. 2011. Spatial and temporal trends of climate change in Xinjiang, China. Journal of Geographical Sciences 21 (6): 1007-1018 DOI 10.1007/s11442-011 -0896-8.

Li, B. F, Chen, Y. N, and Shi, X. 2012. Why does the temperature rise faster in the arid region of northwest China? J Geophys Res 117: D16115 DOI 10.1029/2012JD 017953.

Li BF, Chen ZS, Yuan XZ. 2015. The nonlinear variation of drought and its relation to atmospheric circulation in Shandong Province, East China. PeerJ 3: e1289 DOI 10.7717/peerj.1289

Li, Z, Chen, Y.N, Shen, Y. J, Liu, Y. B, and Zhang, S. H. 2013. Analysis of changing pan evaporation in the arid region of Northwest China. Water Resources Research 49 (4): 2205 2212 DOI 10.1002/wrcr.20202.

Li, Z., Chen, Y.N, W. Li, H. Deng, and G. Fang. 2015. Potential impacts of climate change on vegetation dynamics in Central Asia. J. Geophys. Res. Atmos 120: 12,345-12,356 DOI 10.1002/2015JD023618.

Li, Z., Chen, Y. N., Fang, G. H., Li, Y.P., 2017. Multivariate assessment and attribution of droughts in Central Asia. Scientific Reports. 7: 1316. DOI 10.1038/s41598-017-01473-1. 
Li Y, and Sun, C. 2016a. Impacts of the superimposed climate trends on droughts over 19612013 in Xinjiang, China. Theoretical and Applied Climatology 1-18 DOI 10.1007/s00704016-1822-x.

Li, Y., Yao, N., Sahin, S., and Appels, W. M. 2016b. Spatiotemporal variability of four precipitation-based drought indices in Xinjiang, China. Theoretical and Applied Climatology 1-18 DOI 10.1007/s00704-016-1827-5.

Liu, K., and D. B. Jiang. 2014. Interdecadal change and cause analysis of extreme summer and winter droughts over China. Chin. J. Atmos. Sci. 38(2): 309-321 (in Chinese).

Ma, Z. G., and C. B. Fu. 2006. Some evidence of drying trend over northern China from 1951 to 2004. Chin. Sci. Bull. 51: 2913-2925 DOI 10.1007/s11434-006-2159-0.

Mallya, G., Mishra, V., Niyogi, D., Tripathi, S., and Govindaraju, R. S. 2016. Trends and variability of droughts over the Indian monsoon region. Weather and Climate Extremes 12: 43-68 DOI 10.1016/j.wace.2016.01.002.

Mann HB.1945. Non-parametric tests against trend. Econometrica 13: 245-259 DOI $10.2307 / 1907187$.

McKee, T. B., Doesken, N. J., and Kleist, J. 1993. The relationship of drought frequency and duration to time scales. In Proceedings of the 8th Conference on Applied Climatology (Vol. 17, No. 22, pp. 179-183). Boston, MA: American Meteorological Society.

Meza, F. J. 2013. Recent trends and ENSO influence on droughts in Northern Chile: An application of the Standardized Precipitation Evapotranspiration Index. Weather and Climate extremes 1: 51-58 DOI 10.1016/j.wace.2013.07.002.

Mishra, A.K., and Singh, V.P. 2011. Drought modeling - A review. J. Hydrol 403: 157-175 DOI 10.1016/j.jhydrol.2011.03.049. 
Potop, V., Možný, M., and Soukup, J. 2012. Drought evolution at various time scales in the lowland regions and their impact on vegetable crops in the Czech Republic. Agricultural and Forest Meteorology 156: 121-133 DOI 10.1016/j.agrformet.2012.01.002.

Potop, V., Boroneanţ, C., Možný, M. Štěpánek, P., Skalák, P. 2014. Observed spatiotemporal characteristics of drought on various time scales over the Czech Republic. Theor. Appl. Climatol 115: 563-581 DOI 10.1007/s00704-013-0908-y.

Rayner, D. P. 2007. Wind run changes: the dominant factor affecting panevaporation trends in Australia. J. Clim. 20(14): 3379-3394 DOI 10.1175/ JCLI4181.1.

Rim, C. S. 2012. The implications of geography and climate on drought trend. Int J Climatol DOI 10.1002/joc.3628.

Romm, J. 2011. The next dust bowl. Nature 478: 450-451 DOI 10.1038/478450a.

Rouse, J.W. 1974. Monitoring the vernal advancement of retrogradation of natural vegetation, NASA/GSFC, Type III, Final Report, Greenbelt, MD, p. 371.

\section{Schubert, S. D., Stewart, R. E., Wang, H., Barlow, M., Berbery, E. H., Cai, W., and} Mariotti, A. 2016. Global Meteorological Drought: A Synthesis of Current Understanding with a Focus on SST Drivers of Precipitation Deficits. Journal of Climate 29(11): 39894019 DOI 10.1175/JCLI-D-15-0452.1.

Shen, Z. R., and W. C. He. 1996. Assessment of China's agricultural water use and approach to the solution of existing problems. J. Nat. Resour. 11: 221-230 (in Chinese).

Shi, Y. F, Shen, Y. P, Hu, R. J. 2002. Preliminary study on signal, impact and foreground of climatic shift from warm-dry to warm-humid in Northwest China. Journal of Glaciology and Geocryology 24 (3): 219-226 (in Chinese). 
Shi, Y.F, Shen, Y.P, Li, D.L, Zhang, G.Q, Ding, Y.H, Hu, R.J, Kang, E. 2003. Discussion on the present climate change from warm-dry to warm-wet in northwest China. Quaternary Sciences 23 (2): 152-164 (in Chinese).

Shi, Y., Shen, Y., Kang, E., Li, D., Ding, Y., Zhang, G., and Hu, R. 2007. Recent and future climate change in northwest China. Climatic change 80(3): 379-393 DOI 10.1007/s10584006-9121-7.

Shi, Y. G. 2006. Metelogical disaster in Xinjiang, China. China Meteorological Press: 16pp (in Chinese).

Sun Y, Solomon S, Dai A, and Portmann R. 2006. How often does it rain? J Clim 19: 916-934 DOI 10.1175/JCLI3672.1

Sun, C, and Ma, Y. 2015. Effects of non-linear temperature and precipitation trends on Loess Plateau droughts. Quat Int DOI 10.1016/j.quaint. 2015.01.051.

Svoboda M, LeComte D, Hayes M, Heim R, Gleason K, Angel J, Rippey B, Tinker R, Palecki M, Stooksbury D, Miskus D, and Stephens S. 2002. The drought monitor. Bulletin of the American Meteorological Society 83: 1181-1192 DOI 10.1175/15200477(2002)083.

Sneyers, R. 1990. On statistical analysis of series of observations, WMO Technical note No. 143, WMO No. 415. Geneva, Switzerland, 192 pp

Tao, H., Borth, H., Fraedrich, K., Su, B., and Zhu, X. 2014. Drought and wetness variability in the Tarim River Basin and connection to large-scale atmospheric circulation. International Journal of Climatology 34(8): 2678-2684 DOI 10.1002/joc.3867.

Taylor, C.M., de Jeu, R.A., Guichard, F., Harris, P.P., Dorigo, W.A. 2012. Afternoon rain more likely over drier soils. Nature 489 (7416): 423-426 DOI 10.1038/nature11377. 
Teuling, A.J., van Loon, A.F., Seneviratne, S.I., Lehner, I., Aubinet, M., Heinesch, B., Bernhofer, C., Grunwald, T., Prasse, H., and Spank, U. 2013. Evapotranspiration amplifies European summer drought. Geophys. Res. Lett 40(10): 2071-2075 DOI 10.1002/grl.50495.

Thornthwaite CW. 1948. An approach toward a rational classification of climate. Geographical Review 38(1): 55 - 94 DOI: 10.2307/210739.

Trenberth KE, Branstator GW, and Arkin PA. 1988. Origins of the 1988 North-American drought. Science 242: 1640-1645 DOI 10.1126/science.242.4886.1640.

Vicente-Serrano, S. M., Beguería, S., and López-Moreno, J. I. 2010a. A multiscalar drought index sensitive to global warming: the standardized precipitation evapotranspiration index. Journal of Climate 23(7): 1696-1718 DOI 10.1175/2009JCLI2909.1.

Vicente-Serrano, S.M., Beguería, S., López-Moreno, J.I., Angulo, M., El Kenawy A. $2010 b$. A new global 0.5 gridded dataset (1901-2006) of a multi-scalar drought index: comparison with current drought index datasets based on the Palmer Drought Severity Index. $J$. Hydrometeorol 11: 1033-1043 DOI 10.1175/2010JHM1224.1.

Vicente-Serrano, S. M., López-Moreno, J. I., Lorenzo-Lacruz, J., El Kenawy, A., AzorinMolina, C., Morán-Tejeda, E., and Angulo-Martínez, M. 2011. The NAO impact on droughts in the Mediterranean region. In Hydrological, socioeconomic and ecological impacts of the north Atlantic oscillation in the mediterranean region (pp. 23-40). Springer Netherlands.

Vicente-Serrano, S. M., Lopez-Moreno, J. I., Beguería, S., Lorenzo-Lacruz, J., SanchezLorenzo, A., García-Ruiz, J. M., and Coelho, F. 2014. Evidence of increasing drought severity caused by temperature rise in southern Europe. Environmental Research Letters 9(4): 044001. DOI 10.1088/1748-9326/9/4/044001. 
Vicente-Serrano, S. M., Van der Schrier, G., Beguería, S., Azorin-Molina, C., and LopezMoreno, J. I. 2015. Contribution of precipitation and reference evapotranspiration to drought indices under different climates. Journal of Hydrology 526: 42-54 DOI 10.1016/j.jhydrol.2014.11.025.

Wang, A.H., Lettenmaier, D.P., Sheffield, J. 2011. Soil moisture drought in China, 1950-2006. J. Climate 24: 3257-3271 DOI 10.1175/2011JCLI3733.1.

Wang, H., Chen, Y., and Pan, Y. 2015. Characteristics of drought in the arid region of northwestern China. Climate Research 62(2): 99-113 DOI 10.3354/cr01266

Wang, Y. F, Shen, Y. J, Sun, F. B, and Chen, Y. N. 2014. Evaluating the vegetation growing season changes in the arid region of northwestern China. Theor Appl Climatol 118(3): 569 579, DOI 10.1007/s00704-013-1078-7.

Wang, Q., Shi, P., Lei, T., Geng, G., Liu, J., Mo, X., and Wu, J. 2015. The alleviating trend of drought in the Huang-Huai-Hai Plain of China based on the daily SPEI. International Journal of Climatology 35(13): 3760-3769 DOI 10.1002/joc.4244.

Wang, K. C., and R. E. Dickinson. 2013. Contribution of solar radiation to decadal temperature variability over land. Proc. Natl. Acad. Sci. U.S.A. 110(37): 14,877-14,882 DOI 10.1073/pnas. 1311433110 .

Wang, X.J., Zhang, J.Y., Shamsuddin, S., Amgad, E., He, R.M., Bao, Z.X., and Ali, M. 2012. Water resources management strategy for adaptation to droughts in China. Mitigat. Adaptat. Strategies Global Change 17 (8): 923-937 DOI 10.1007/s11027-011-9352-4.

Wilhite, D. A. and M. H. Glantz. 1985. Understanding the drought phenomenon: The role of definitions. Water Int. 10: 111-120,

Wilhite, D. A. 1993. Drought Assessment, Management, and Planning: Theory and Case Studies. Natural Resource Management and Policy Series, Vol. 2, Kluwer, 293 pp. 
Willmott, C. J., C. M. Rowe, and Y. Mintz. 1985. Climatology of the terrestrial seasonal water cycle. J. Climatol., 5: 589-606 DOI 10.1002 / joc.3370050602

World Meteorological Organization. 2012. Standardized Precipitation Index User Guide (Svoboda, M., Hayes, M., Wood, D.), WMO-No. 1090, Geneva.

Wu, Z.Y., Lu, G.H., Wen, L., and Lin, C.A. 2011. Reconstructing and analyzing China's fiftynine year (1951-2009) drought history using hydrological model simulation. Hydrol. Earth Syst. Sci. Discuss 8 (1): 1861-1893 DOI 10.5194/hess-15-2881-2011.

Xu, Z. X, Chen, Y. N, and Li, J. Y. 2004. Impact of climate change on water resources in the Tarim River basin. Water Resour Manag 18: 439 - 458 DOI 10.1023/B:WARM.0000049142.95583.98

Xu, C, Chen, Y. N, Yang, Y, Hao, X, Shen, Y. 2010. Hydrology and water resources variation and its response to regional climate change in Xinjiang. Journal of Geographical Sciences 20(4): 599-612 DOI 10.1007/s11442-010-0599-6.

Xu, K., Yang, D., Yang, H., Li, Z., Qin, Y., and Shen, Y. 2015a. Spatio-temporal variation of drought in China during 1961-2012: A climatic perspective. Journal of Hydrology 526: 253-264 DOI 10.1016/j.jhydro1.2014.09.047.

Xu, C., Li, J., Zhao, J., Gao, S., and Chen, Y. 2015b. Climate variations in northern Xinjiang of China over the past 50 years under global warming. Quat Int 358: 83-92 DOI 10.1016/j.quaint.2014.10. 025.

Xu JH, Chen YN, Li WH, Liu ZH, Wei CM, Tang J. 2013. Understanding the complexity of temperature dynamics in Xinjiang, China, from multitemporal scale and spatial perspectives. The Scientifi c World Journal DOI 10.1155/2013/259248. 
Yang, P., Xiao, Z., Yang, J., and Liu, H. 2013. Characteristics of clustering extreme drought events in China during 1961-2010. Acta Meteorol. Sin 27(2): 186-198 DOI 10.1007/s13351-013-0204-X.

Yang, Y. H., J. Y. Fang, W. H. Ma, P. Smith, A. Mohammat, S. P. Wang, and W. Wang. 2010. Soil carbon stock and its changes in northern China's grasslands from 1980s to 2000s. Global Change Biol. 16: 3036 - 3047 DOI 10.1111/j.1365-2486. 2009.02123.x.

Yang, D, Sun, F, Liu, Z, Cong, Z, Ni, G, and Lei, Z. 2007. Analyzing spatial and temporal variability of annual water-energy balance in nonhumid regions of China using the Budyko hypothesis. Water Resour Res 43: W04426 DOI 10.1029/2006WR005224.

Yao, J. Q, Mao, W. Y, Yang, Q, Xu, X., and Liu, Z. 2016. Annual actual evapotranspiration in inland river catchments of China based on the Budyko framework. Stoch Environ Res Risk Assess 30 DOI 10.1007/s00477-016-1271-1.

Yao, J. Q, Chen, Y. N, Zhao, Y, Mao, W., Xu, X., Liu, Y., and Yang, Q. 2017. Response of vegetation NDVI to climatic extremes in the arid region of Central Asia: a case study in Xinjiang, China. Theoretical and Applied Climatology DOI 10.1007/s00704-017-2058-0.

Yao, J. Q, Zhao, Y., Chen, Y. N., Yu, X. J., Zhang, R. B. 2018. Multi-scale assessments of droughts: A case study in Xinjiang, China. Science of the Total Environment 630: 444-452 DOI org/10.1016/j.scitotenv.2018.02.200

Yu, M., Li, Q., Hayes, M.J., Svoboda, M.D., and Heim, R.R. 2014. Are droughts becoming more frequent or severe in China based on the Standardized Precipitation Evapotranspiration Index: 1951-2010? Int. J. Climatol 34 (3): 545-558 DOI $10.1002 /$ joc. 3701

Zeng, F. W, Collatz, G. J, Pinzon, J. E, and Ivanoff, A. 2013. Evaluating and quantifying the climate-driven interannual variability in global inventory modeling and mapping studies 
672

673

674

675

676

677

678

679

680

681

682

683

684

685

686

687

688

689

690

691

692

693

694

695

(GIMMS) normalized difference vegetation index (NDVI3g) at global scales. Remote Sens 5(8): 3918-3950 DOI 10.3390/rs5083918.

Zhai, J., Su, B., Krysanova, V., Vetter, T., Gao, C., and Jiang, T. 2010. Spatial variation and trends in PDSI and SPI indices and their relation to streamflow in 10 large regions of China. Journal of Climate 23(3): 649-663 DOI 10.1175/2009JCLI2968.1.

Zhao, Y, Yu, Z, and Chen, F. 2009. Spatial and temporal patterns of Holocene vegetation and climate changes in arid and semi-arid China. Quaternary International 194 (1): 6-18 DOI 10.1016/j.quaint. 2007.12.002.

Zhang, A. and Jia, G. 2013. Monitoring meteorological drought in semiarid regions using multi-sensor microwave remote sensing data. Remote Sens. Environ 134: 12-23 DOI 10.1016/j.rse.2013.02.023.

Zhang, Q., Li, J., Singh, V. P., and Bai, Y. 2012. SPI-based evaluation of drought events in Xinjiang, China. Natural hazards 64(1): 481-492 DOI 10.1007/s11069-012-0251-0.

Zhang, Q., Sun, P., Li, J., Xiao, M., and Singh, V. P. 2015. Assessment of drought vulnerability of the Tarim River basin, Xinjiang, China. Theoretical and Applied Climatology 121(1-2): 337-347 DOI 10.1007/s00704-014-1234-8.

Zhang, Q., Han, L., Jia, J., Song, L., and Wang, J. 2016. Management of drought risk under global warming. Theoretical and Applied Climatology 125(1-2): 187-196 DOI 10.1007/s00704-015-1503-1.

Zhang, L., and Zhou, T. 2015. Drought over East Asia: a review. Journal of Climate 28(8): 3375-3399 DOI 10.1175/JCLI-D-14-00259.1.

Zhu, Z., Bi, J., Pan, Y., Ganguly, S., Anav, A., Xu, L., Samanta, A., Piao, S., Nemani, RR., and Myneni, R. B. 2013. Global data sets of vegetation leaf area index (LAI) $3 g$ and Fraction of Photosynthetically Active Radiation (FPAR) 3g derived from Global Inventory 
696 Modeling and Mapping Studies (GIMMS) Normalized Difference Vegetation Index

697 (NDVI3g) for the period 1981 to 2011. Remote Sensing 5(2): 927-948 DOI

$698 \quad 10.3390 /$ rs5020927.

699 
Table $\mathbf{1}$ (on next page)

Drought classifications of SPI and SPEI 
Table 1. Drought classifications of SPI and SPEI.

\begin{tabular}{|c|c|}
\hline Category & Index value \\
\hline Extremely wet & Value $\geq 2$ \\
\hline Moderately wet & $1.5 \leq$ Value $<1.99$ \\
\hline Slightly wet & $1 \leq$ Value $<1.49$ \\
\hline Near normal & $-0.99<$ Value $<0.99$ \\
\hline Mild drought & $-1.49<$ Value $\leq-1$ \\
\hline Moderate drought & $-1.99<$ Value $\leq-1.5$ \\
\hline Extreme drought & Value $\leq-2$ \\
\hline
\end{tabular}


Table 2 (on next page)

Temporal changes of (a) annual mean temperature (b) and annual precipitation in Xinjiang during 1961-2015. 


\section{Manuscript to be reviewed}

Table 2. Mean value and tendency of soil moisture at each depth $(0-50 \mathrm{~cm})$ in Xinjiang

\begin{tabular}{|c|c|c|c|c|c|c|}
\hline Depth (cm) & $\mathbf{0 \sim 5 0}$ & $\mathbf{0} \sim \mathbf{1 0}$ & $\mathbf{1 0 \sim 2 0}$ & $\mathbf{2 0 \sim 3 0}$ & $\mathbf{3 0 \sim 4 0}$ & $\mathbf{4 0 \sim 5 0}$ \\
\hline Mean Value (\%) & 11.3 & 9.5 & 10.7 & 11.5 & 12.0 & 12.9 \\
\hline Trend (\%/10a) & $-3.8^{*}$ & $-3.6^{*}$ & $-4.0^{*}$ & $-3.5^{*}$ & $-3.0^{*}$ & $-2.3^{*}$ \\
\hline
\end{tabular}




\section{Figure 1}

Study area and meteorological stations in Xinjiang (Yao et al., 2018).

Blue box represents the Kaidu River basin.

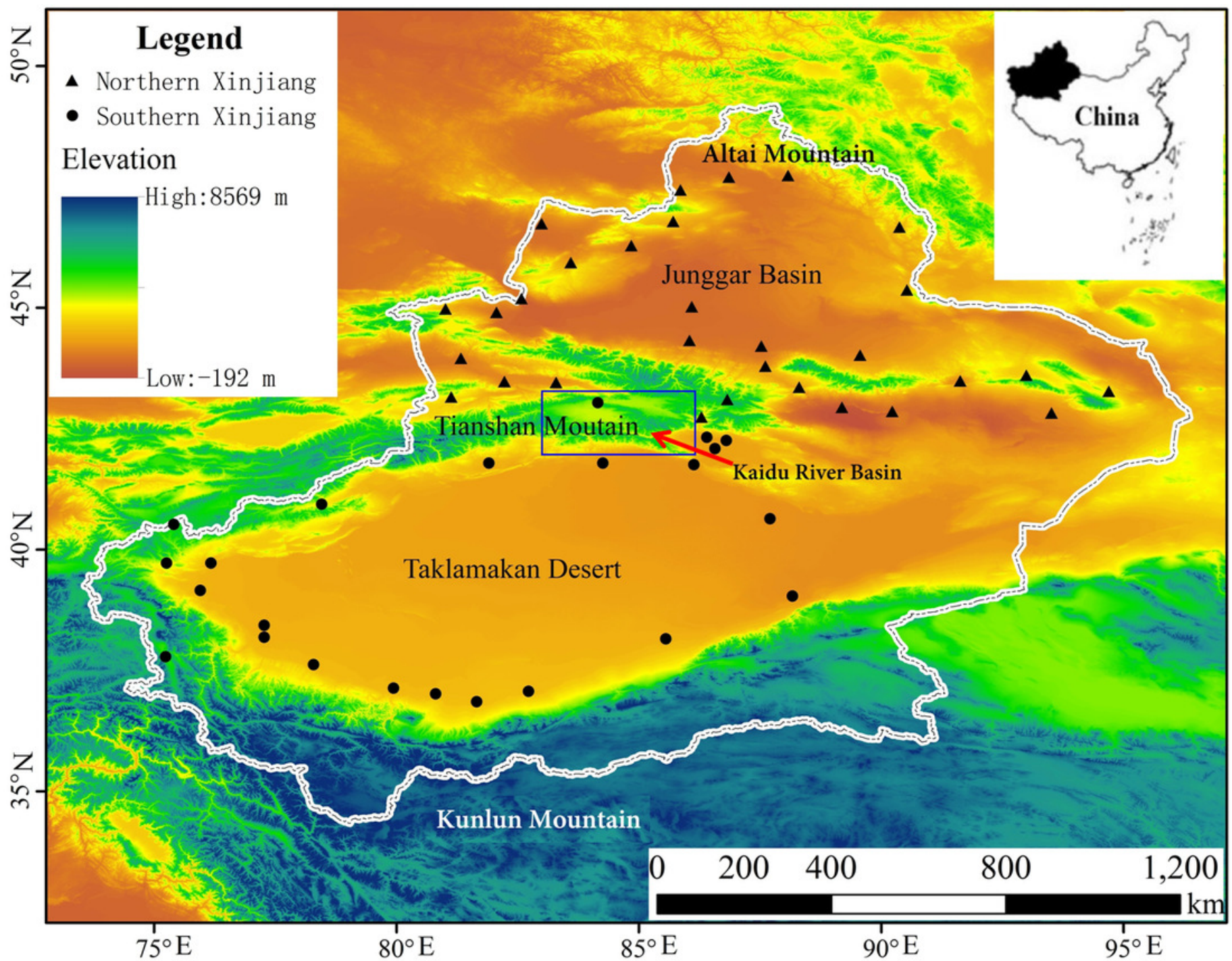


Figure 2

Temporal changes of (a) annual mean temperature (b) and annual precipitation in Xinjiang during 1961-2015.
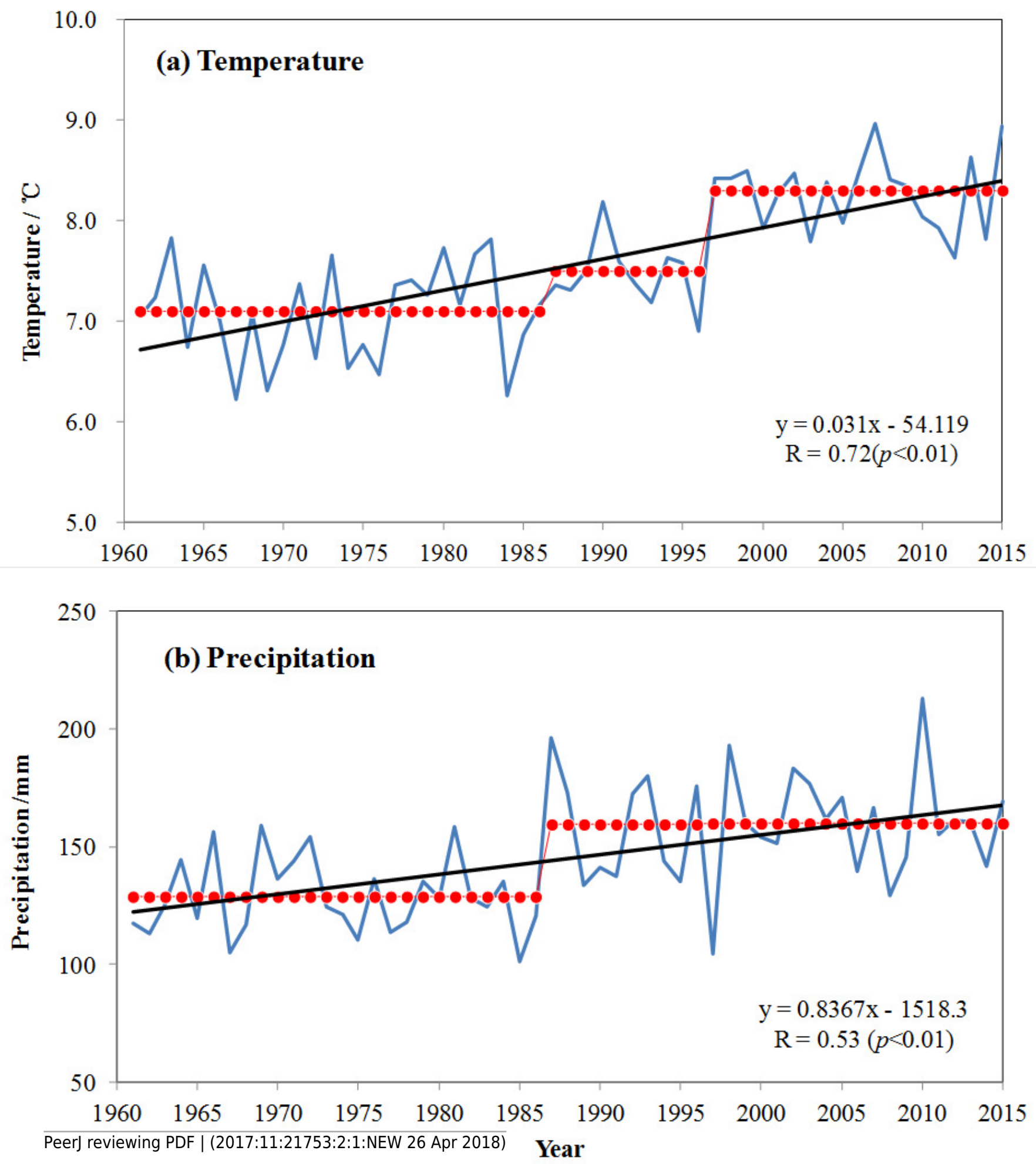
Figure 3

Evolution of the 1-, 3-, 6-, and 12- month SPEI (a-d) and SPI (e-h) for the Xinjiang, China
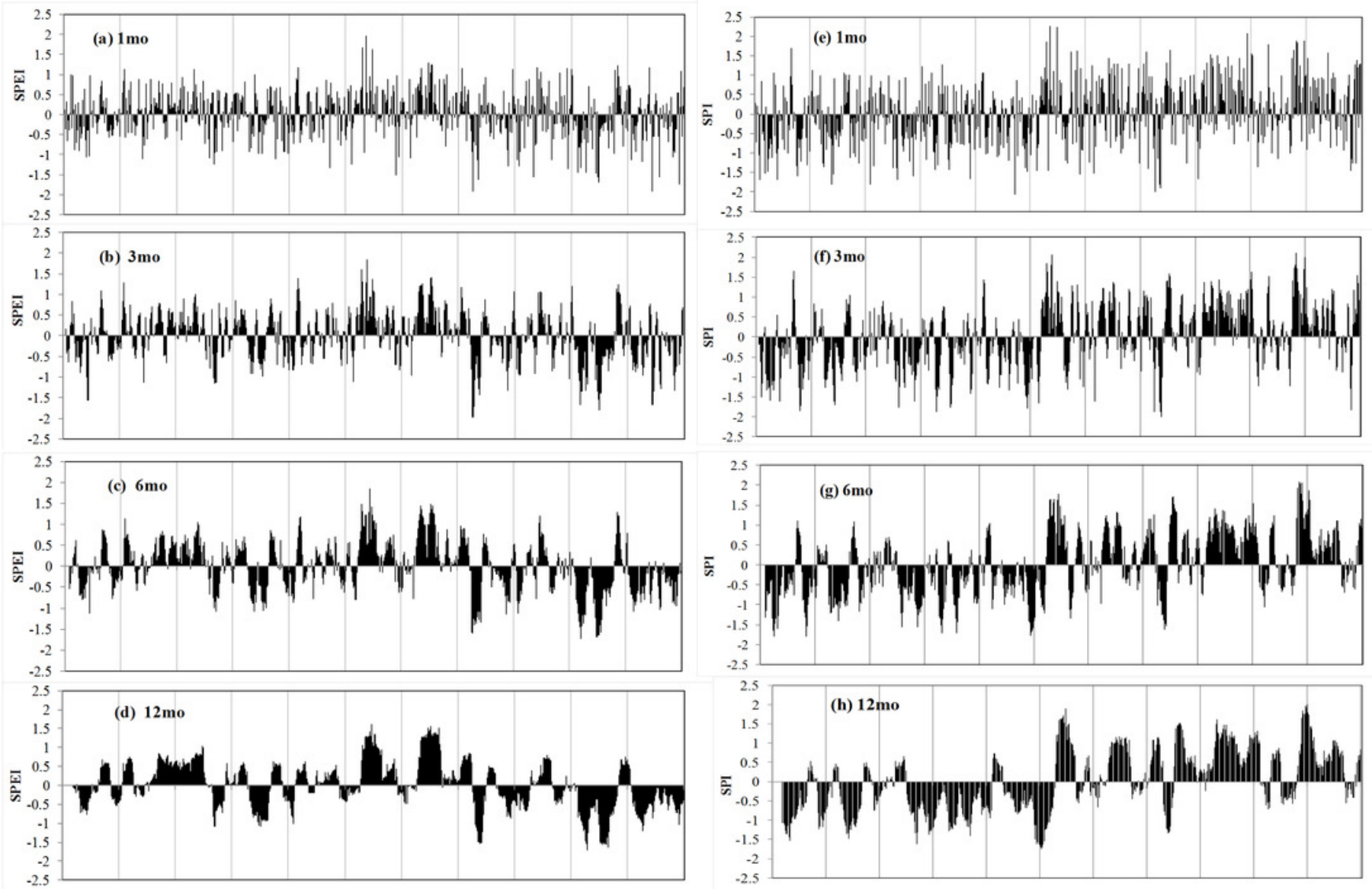
Figure 4

The difference between SPEI and SPI at 1-, 3-, 12- and 48-month lags, the ordinate denotes the value using SPEI minus SPI. 

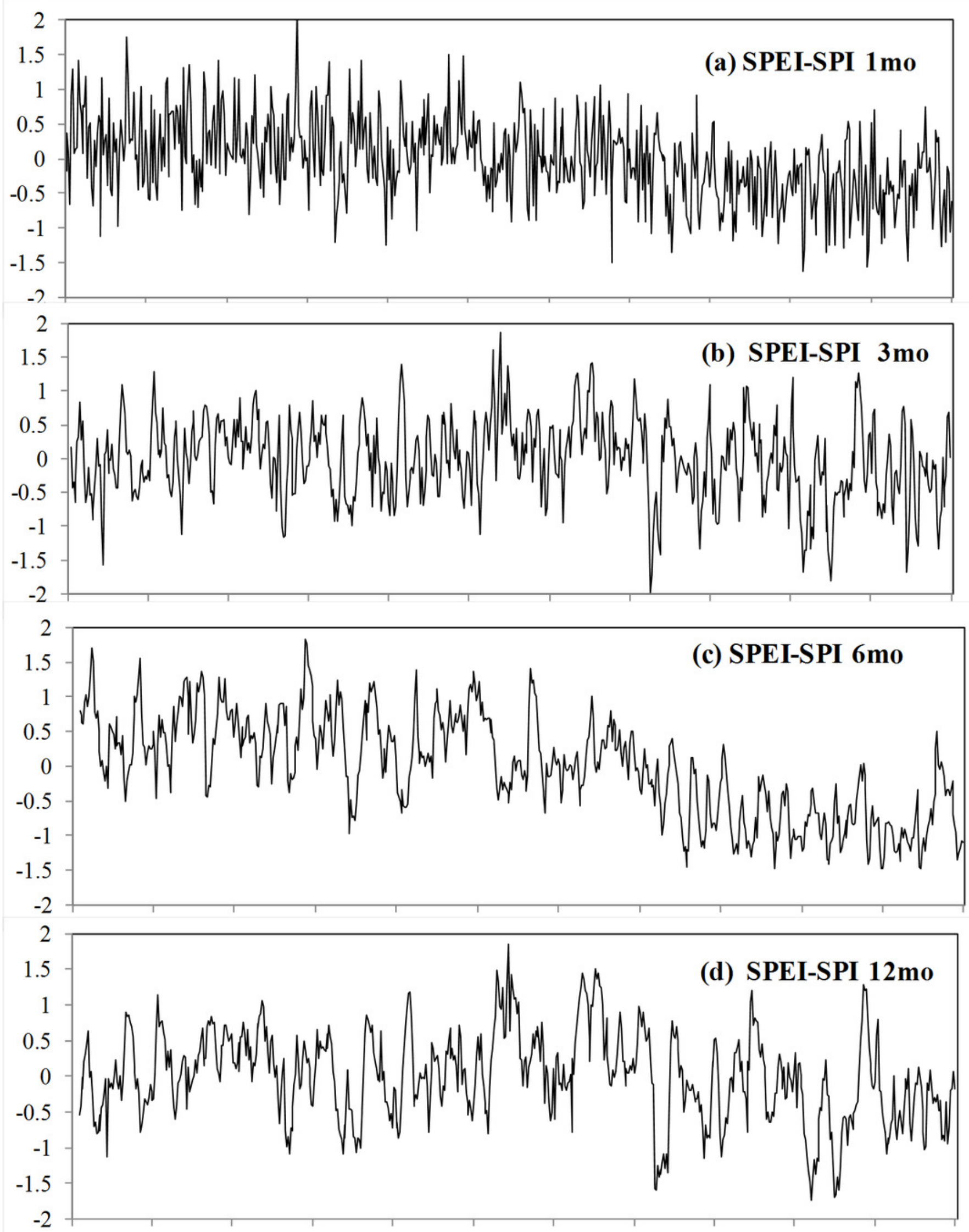

1961-1 1966-1 1971-1 1976-1 1981-1 1986-1 1991-1 1996-1 2001-1 2006-1 2011-1 2016-1 


\section{Figure 5}

Pearson's $r$ correlations between the time series of the two drought indices of the 1-, 3-, 6-, and 12- month SPI (X axis) and SPEI (Y axis) for the whole Xinjiang (a-d), Northern Xinjiang (d-h) and Southern Xinjiang(i-l) during the 1961-2015.
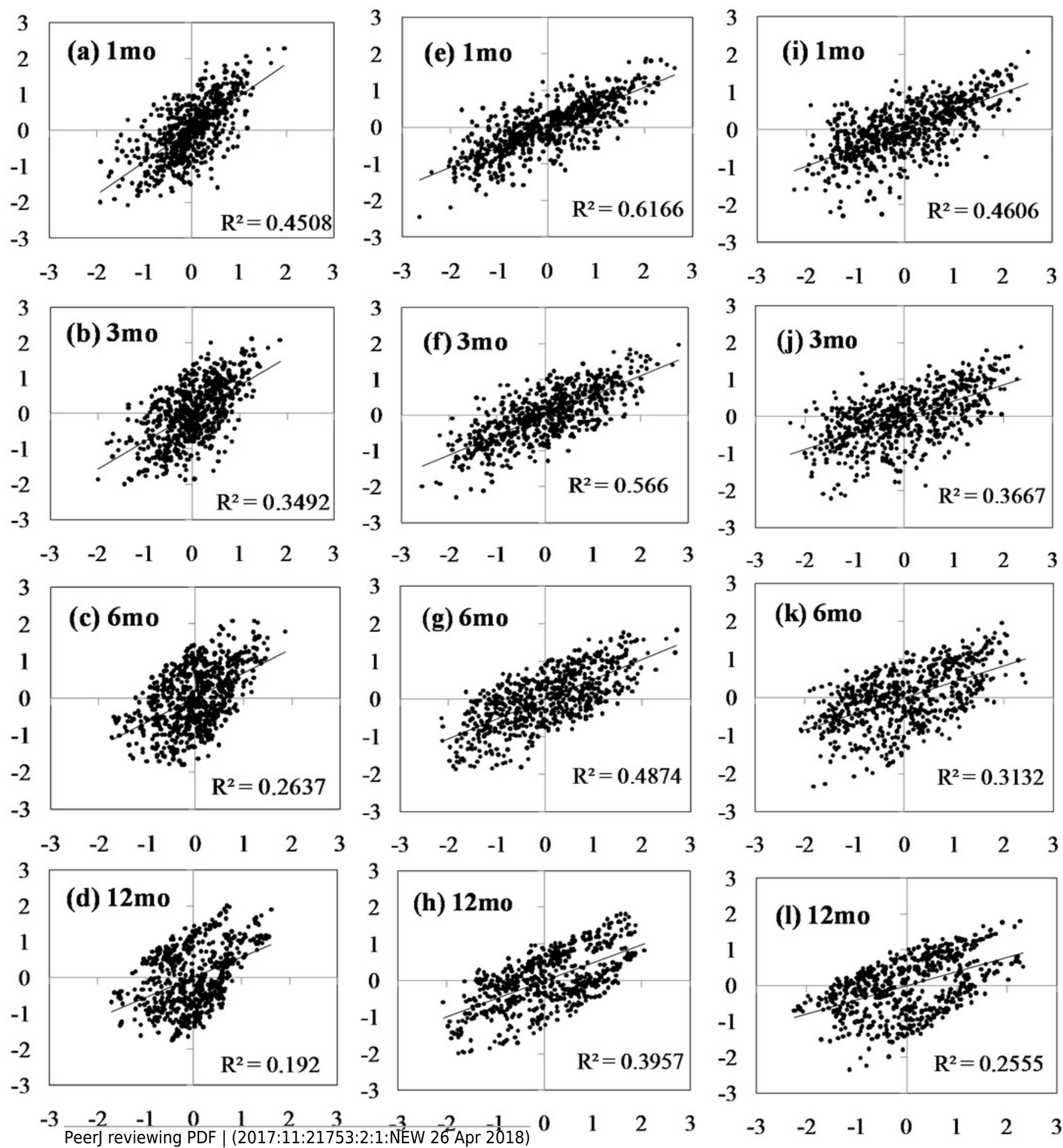

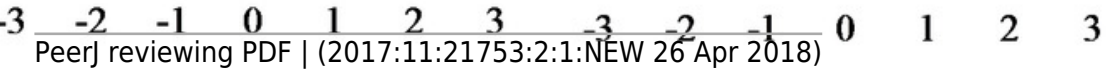


Figure 6

Evolution of the regional SPI (blue line)) and the SPEI (red line) for the Xinjiang from 1961 to 2015 (a), the scatter diagram of the SPI and SPEI at the both episodes (b. 19611996; c. 1997-2015)
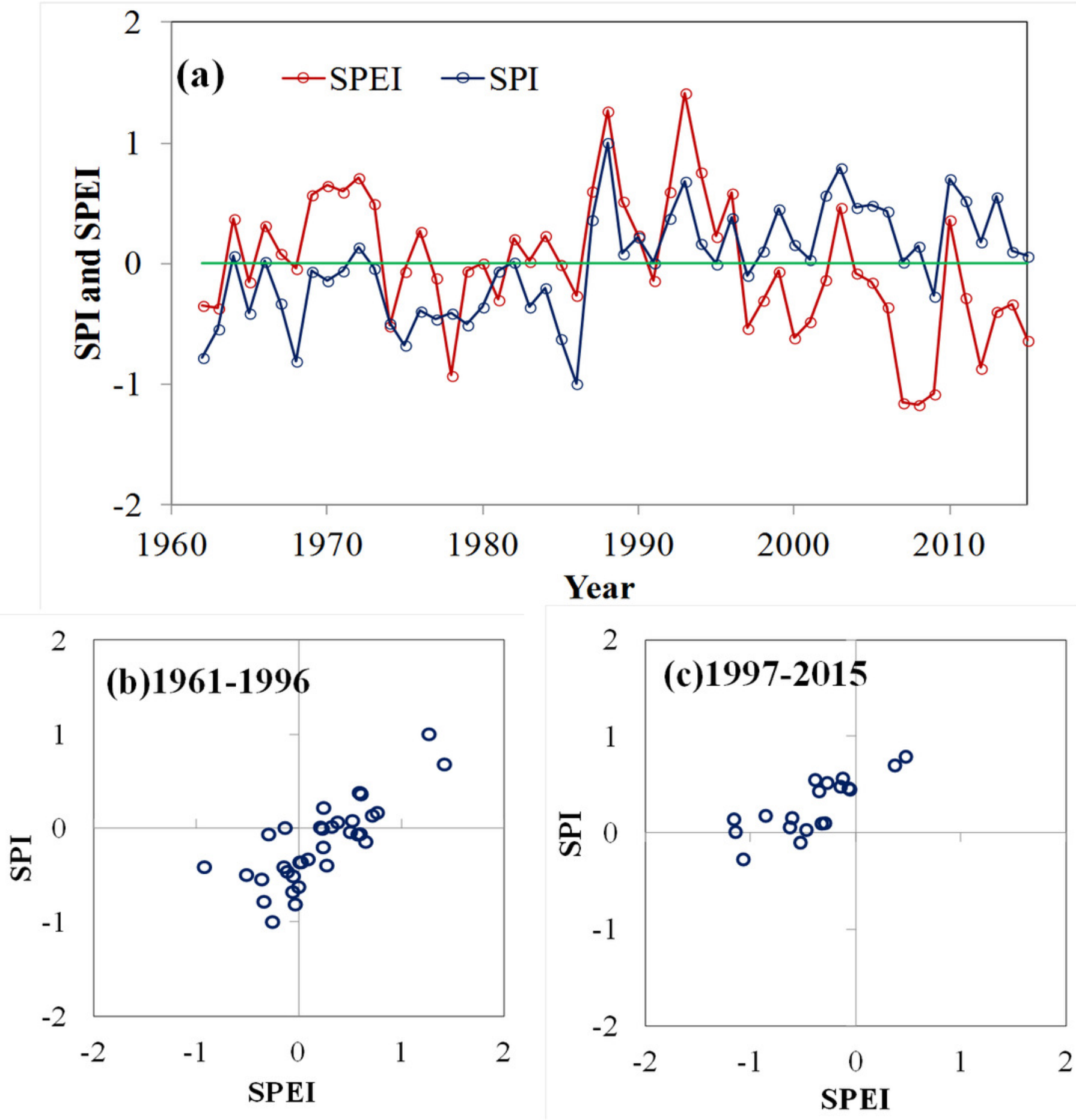
Figure 7

The spatial distribution of the temporal trends per decade in 12- monthly SPI and the 12- monthly SPEI for the period 1961-1996 and 1997-2015 in the Xinjiang.

(a) SPI: 1961-1996

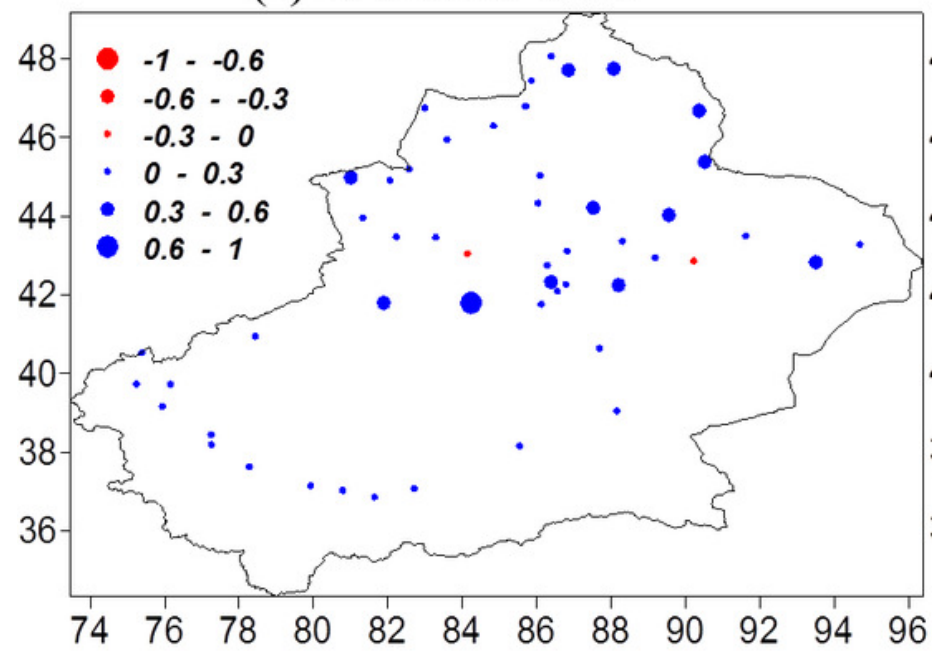

(c) SPEI: 1961-1996

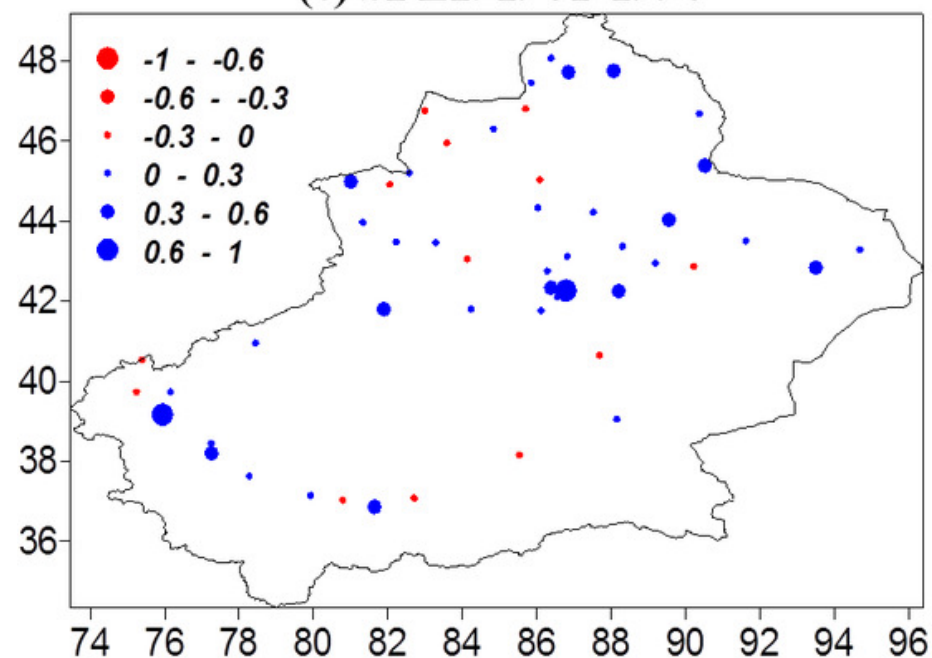

(b) SPI: 1997-2015

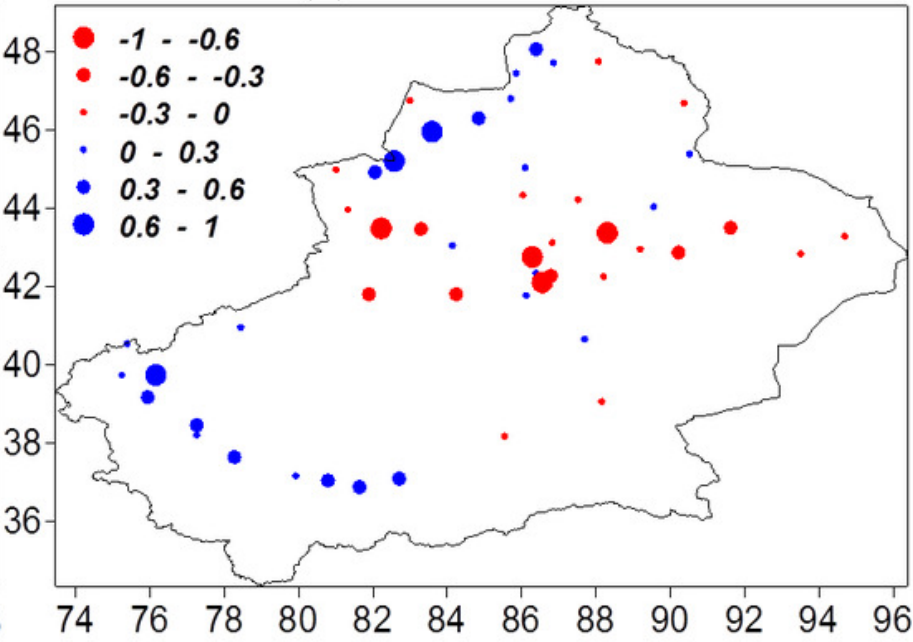

(d) SPEI: 1997-2015

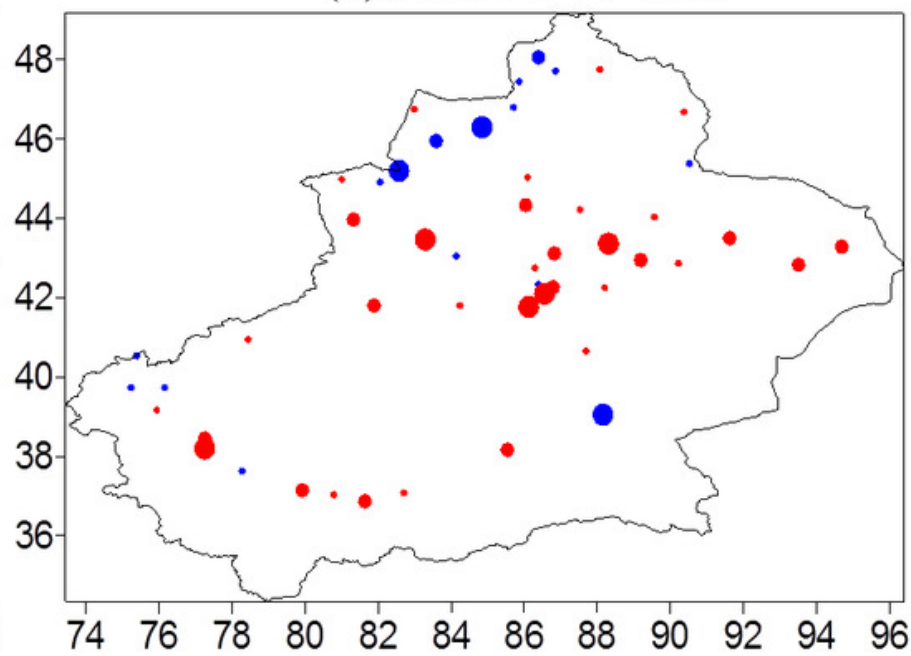


Figure 8

Evolution of the standardized Thornthwaite ET (red line) and pan evaporation (blue line) in Xinjiang. The Pearson's $r$ correlation for the common period (1961-2010) was 0.87 ( $p$ $<0.01$ )

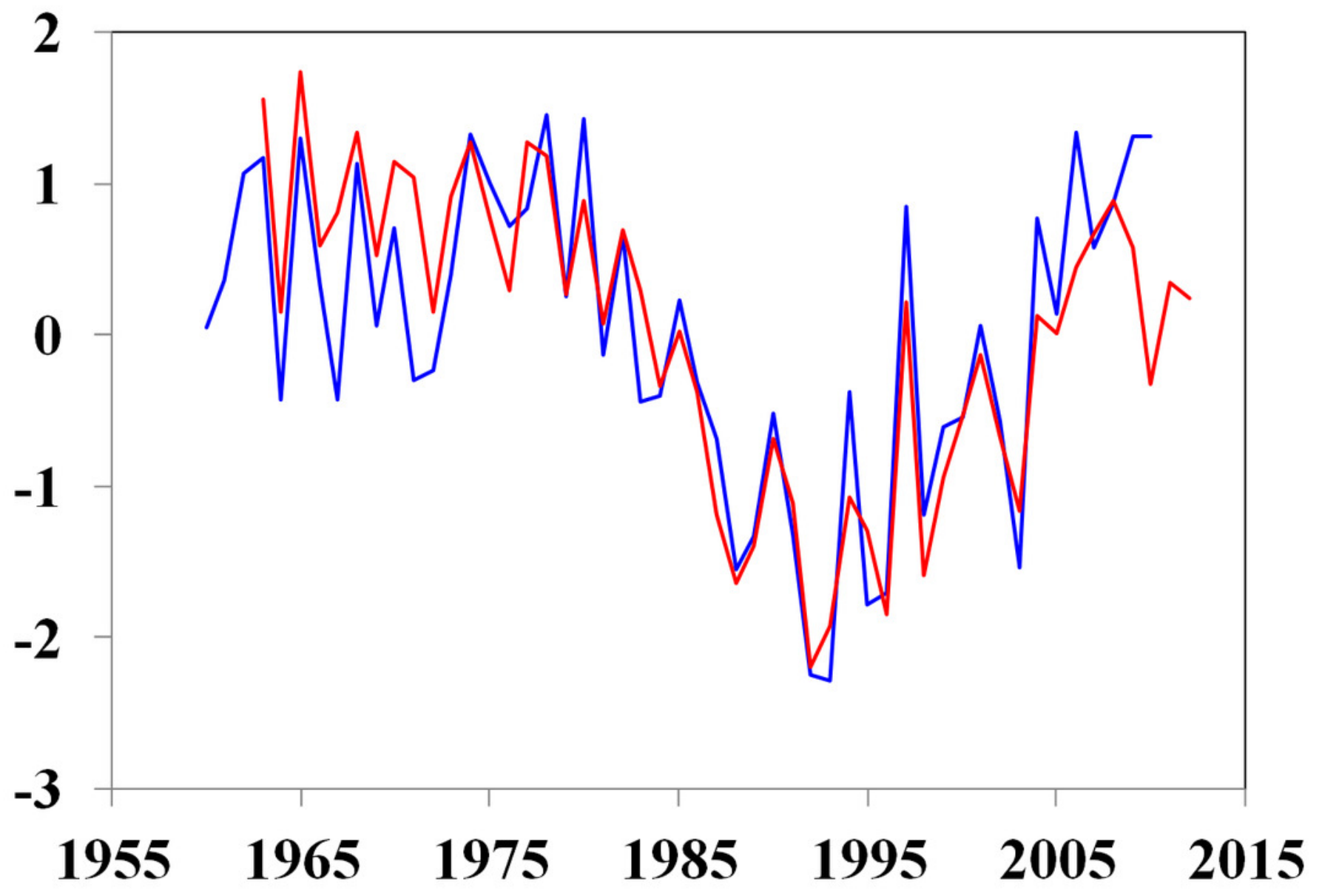


Figure 9

The mean number of dry (SPEI $\leq-1$ ) and wet months (SPEI $\geq 1$ ) each year by the 12month time scale from 1962 to 2015

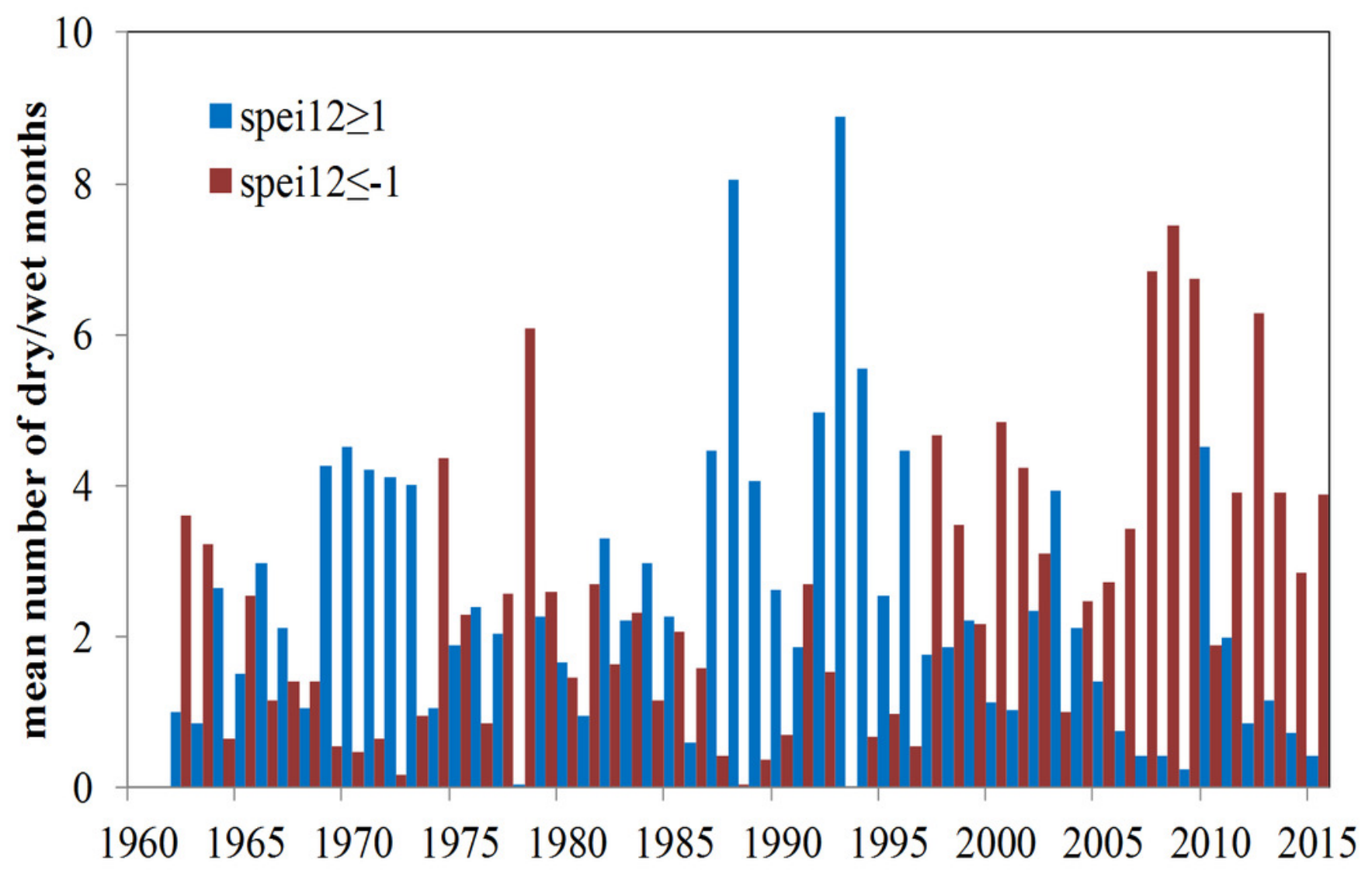


Figure 10

The mean number of dry months (SPEI $\leq-1$ ) each year from 1961 to 2015

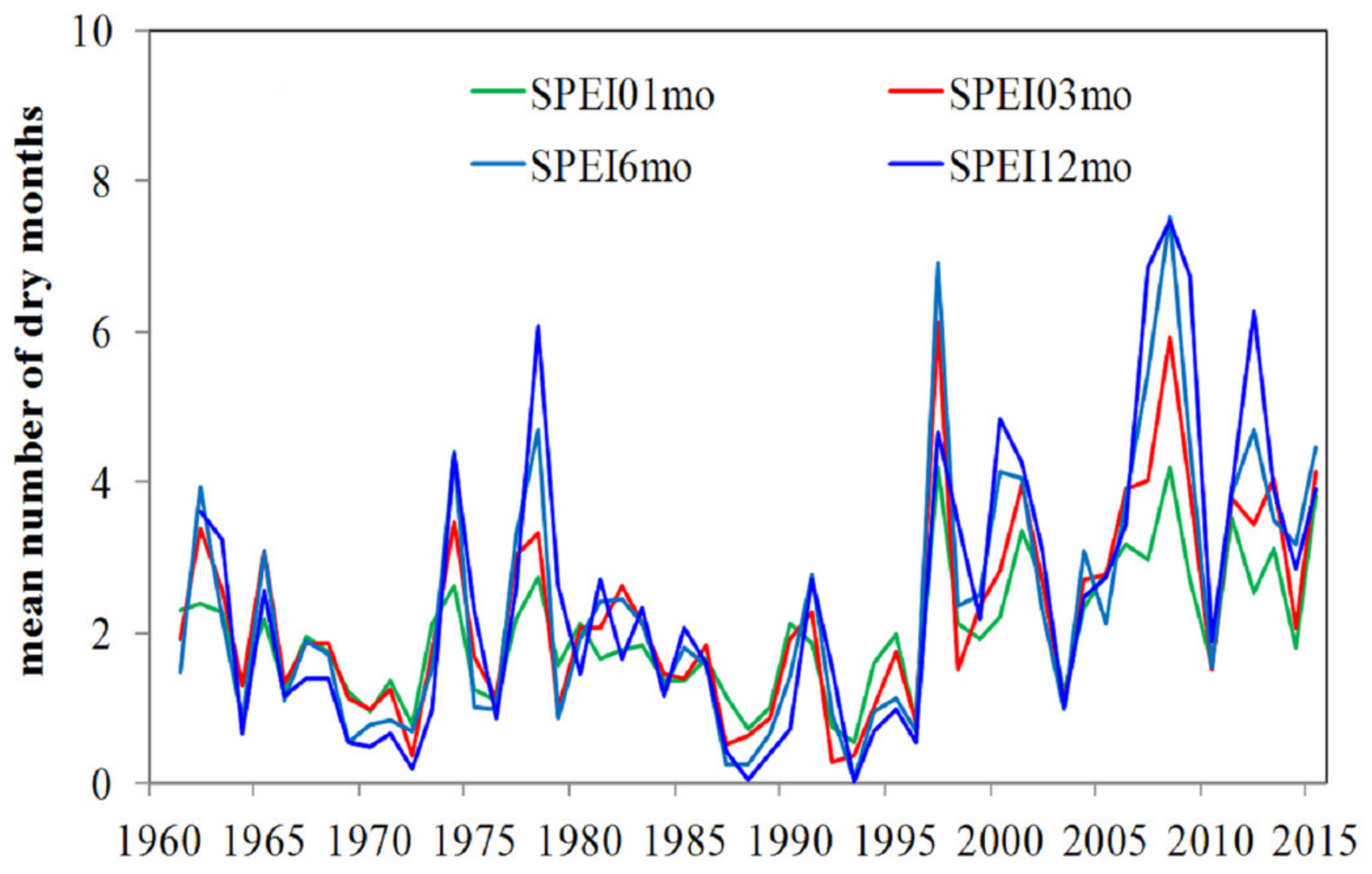


Figure 11

Percentage of stations with more than three dry months and more than six dry months each year

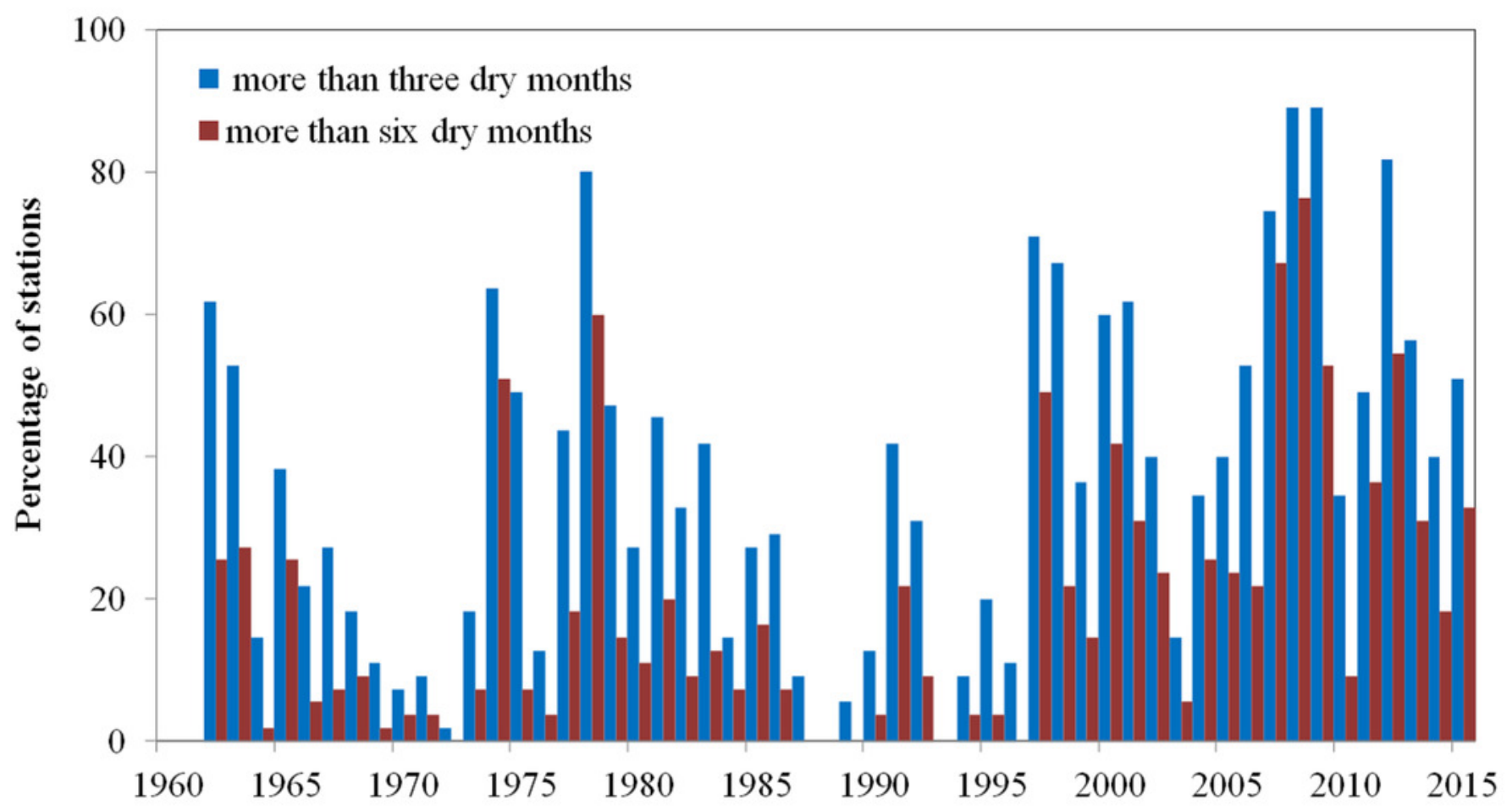


Figure 12

Spatial variations of severe drought events: (a) 1974, (b) 2008, (c) 2009, and (d) 2012

(a) SPEI of 1974

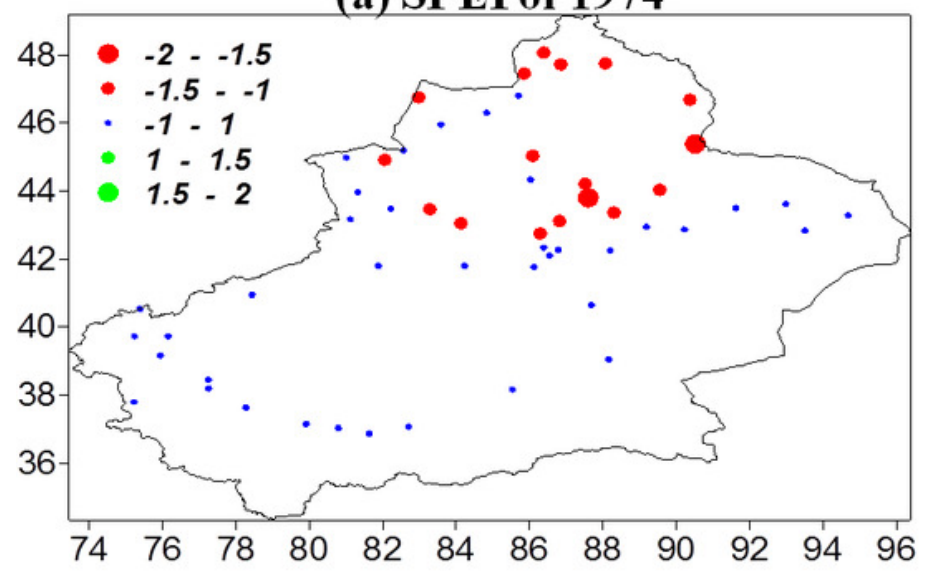

(c) SPEI of 2009

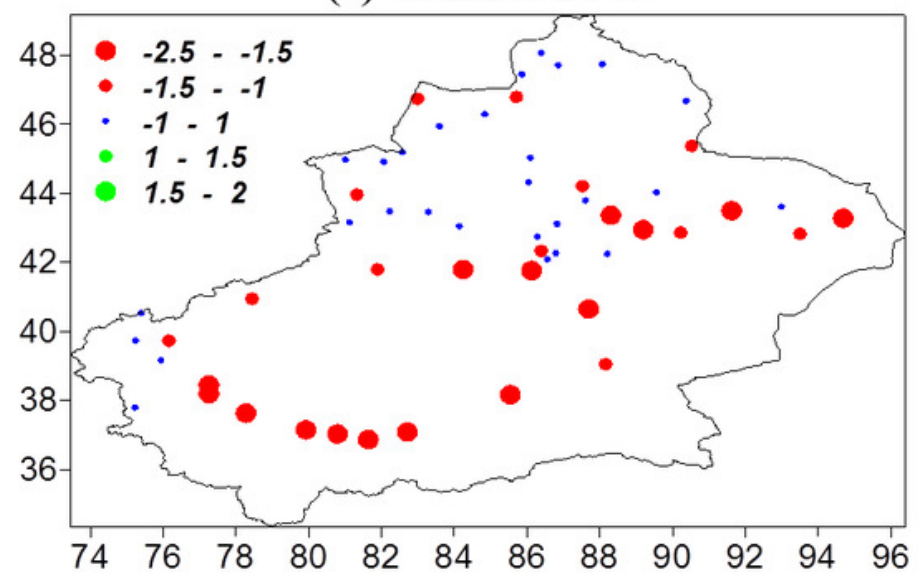

(b) SPEI of 2008

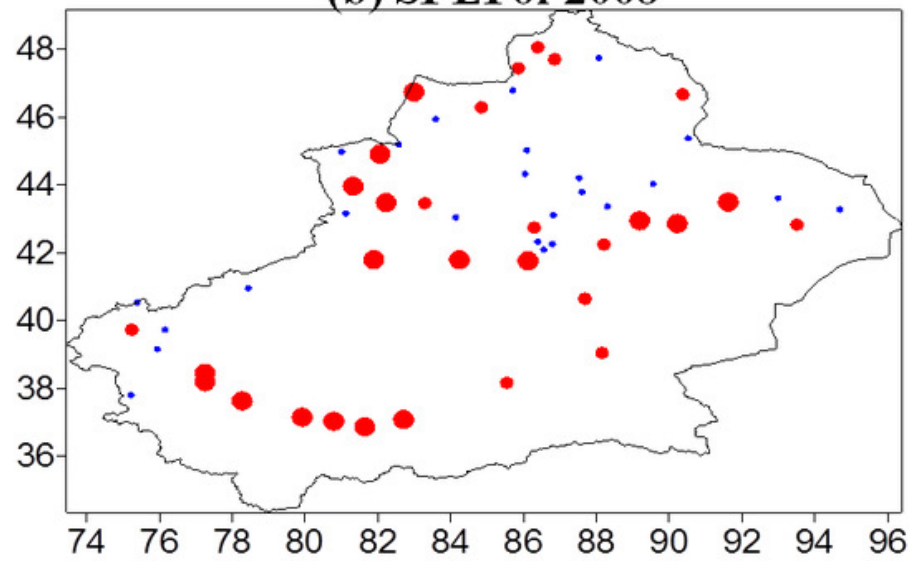

(d) SPEI of 2012

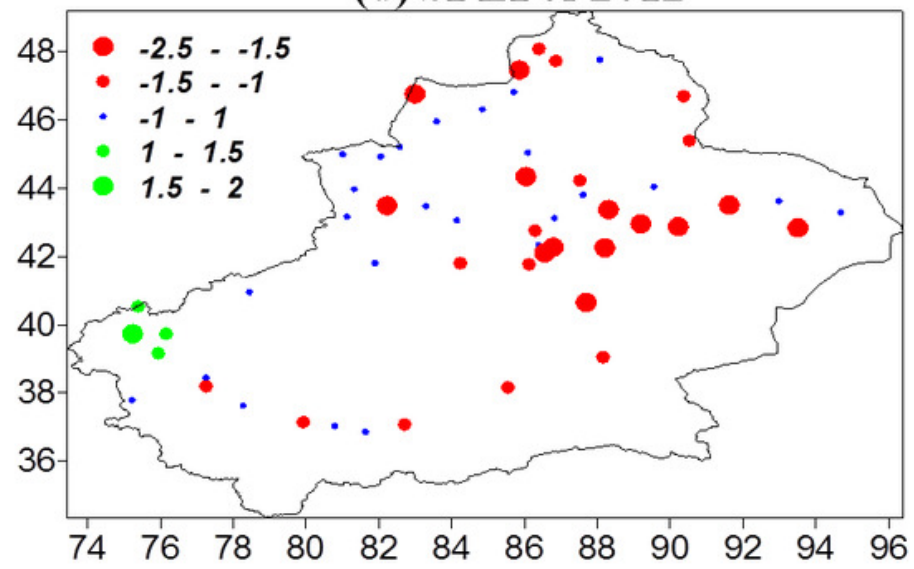


Figure 13

Annual variation of soil moisture at each depth $(0-50 \mathrm{~cm})$ in Xinjiang, China

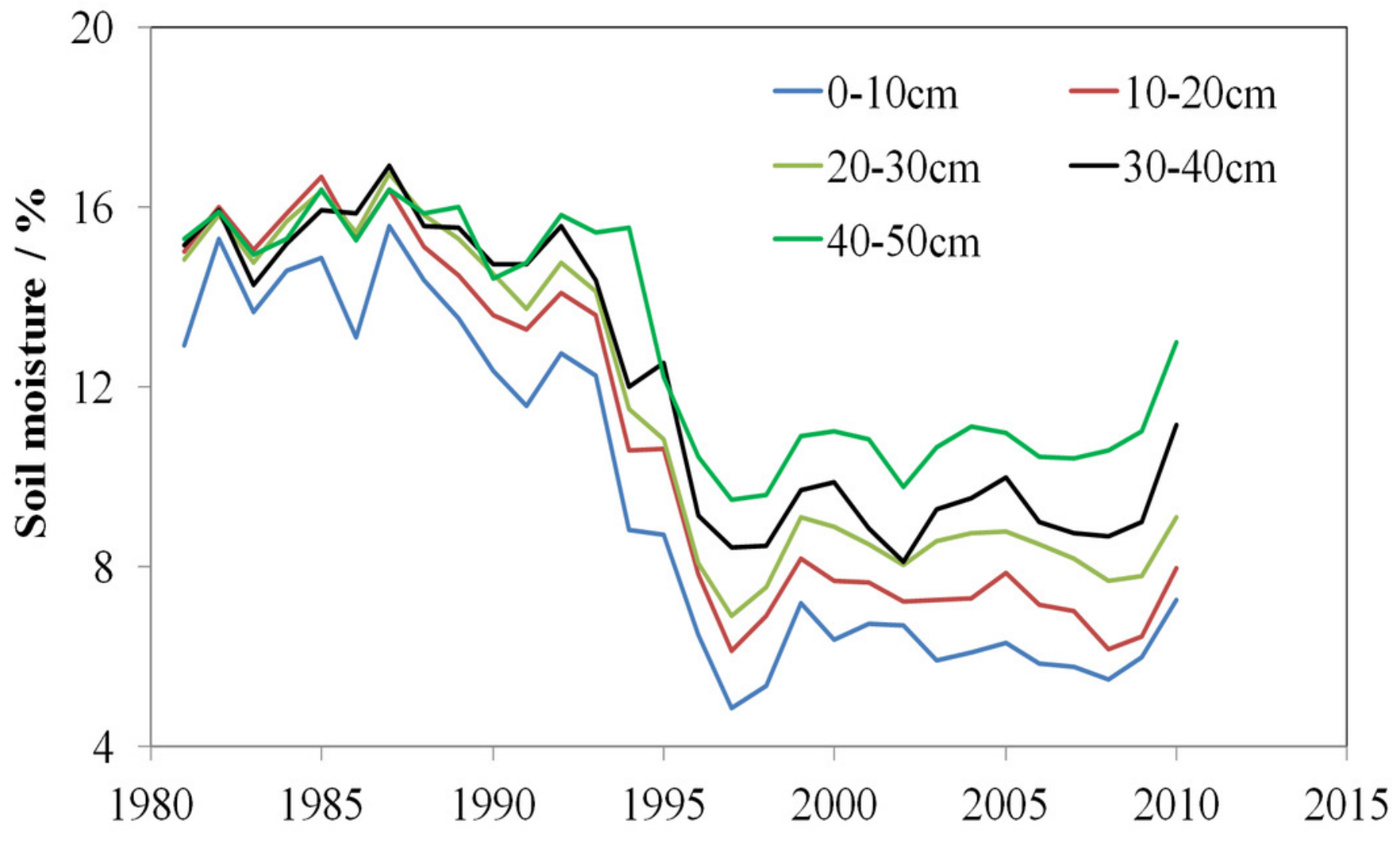




\section{Figure 14}

Evolution of parameters in the Kaidu River basins of the southern Xinjiang, China

Evolution of parameters in the Kaidu River basins of the southern Xinjiang, China, including:

(a) total annual precipitation; (b) total annual streamflow at the Dashankou hydrological

station; (c) runoff coefficient (ratio between precipitation and streamflow); and (d) SPI and SPEI at the Bayinbuluke climate station; and (e) water level at the Bosten Lake. 

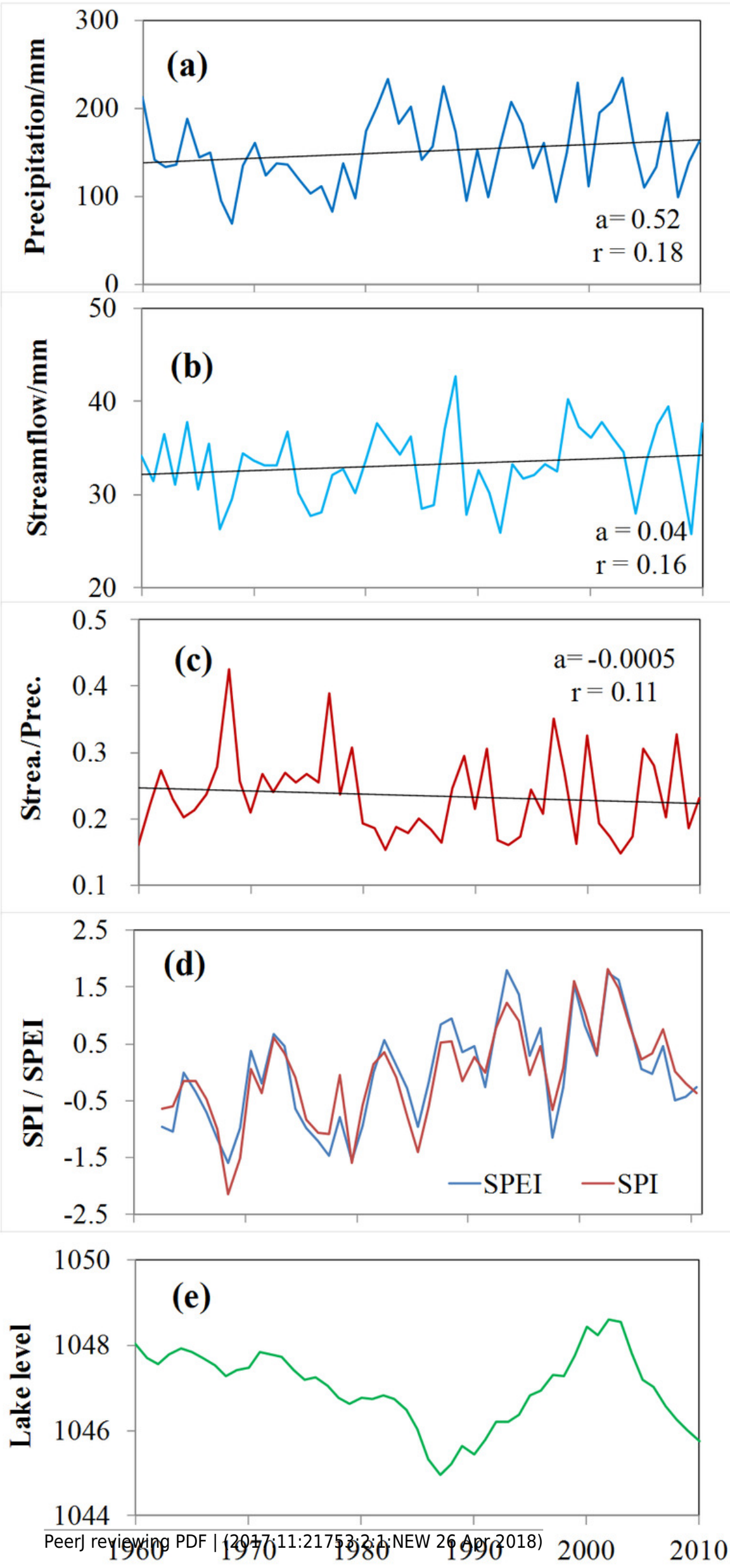
Figure 15

The scatterplot between annual ET and the annual streamflow/precipitation ratio of the 68 inland river catchments in northwestern China

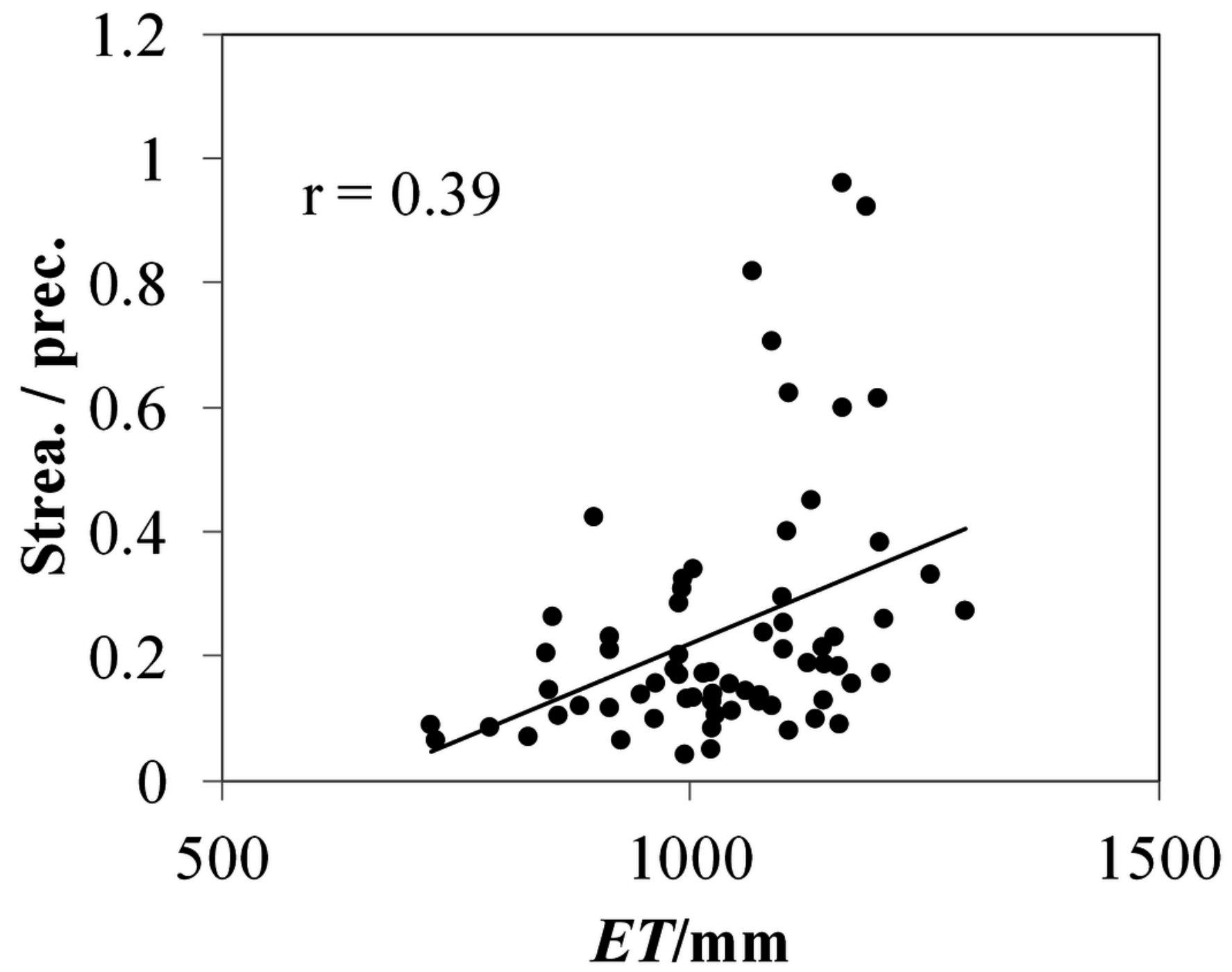

